\title{
Dipeptidyl Peptidase-Like Protein 6 Is Required for Normal Electrophysiological Properties of Cerebellar Granule Cells
}

\author{
Brian M. Nadin and Paul J. Pfaffinger \\ Department of Neuroscience, Baylor College of Medicine, Houston, Texas 77030
}

In cerebellar granule (CG) cells and many other neurons, A-type potassium currents play an important role in regulating neuronal excitability, firing patterns, and activity-dependent plasticity. Protein biochemistry has identified dipeptidyl peptidase-like protein 6 (DPP6) as an auxiliary subunit of Kv4-based A-type channels and thus a potentially important regulator of neuronal excitability. In this study, we used an RNA interference (RNAi) strategy to examine the role DPP6 plays in forming and shaping the electrophysiological properties of CG cells. DPP6 RNAi delivered by lentiviral vectors effectively disrupts DPP6 protein expression in CG cells. In response to the loss of DPP6, $I_{\mathrm{SA}}$ peak conductance amplitude is reduced by $>85 \%$ in parallel with a dramatic reduction in the level of $I_{\mathrm{SA}}$ channel protein complex found in CG cells. The $I_{\mathrm{SA}}$ channels remaining in CG cells after suppression of DPP6 show alterations in gating similar to Kv4 channels expressed in heterologous systems without DPP6. In addition to these effects on A-type current, we find that loss of DPP6 has additional effects on input resistance and $\mathrm{Na}^{+}$channel conductance that combine with the effects on $I_{\mathrm{SA}}$ to produce a global change in excitability. Overall, DPP6 expression seems to be critical for the expression of a high-frequency electrophysiological phenotype in CG cells by increasing leak conductance, A-type current levels and kinetics, and $\mathrm{Na}^{+}$current amplitude.

\section{Introduction}

Excitability, firing frequency, action potential (AP) backpropagation, and synaptic plasticity are regulated by a somatodendritic A-type potassium current $\left(I_{\mathrm{SA}}\right)$ that is active at subthreshold potentials (Hoffman et al., 1997; Ramakers and Storm, 2002; Watanabe et al., 2002; Cai et al., 2004; Jerng et al., 2004b). The $I_{\text {SA }}$ channel is proposed to be a multiprotein complex in which a Kv4 channel $\alpha$-subunit forms the ion conducting core of the channel (Serôdio and Rudy, 1998; Shibata et al., 2000; Rhodes et al., 2004; Chen et al., 2006; Lauver et al., 2006; Covarrubias et al., 2008; Marionneau et al., 2009). In cerebellar granule (CG) cells, Kv4 overexpression and dominant-negative studies have been used to manipulate $I_{\mathrm{SA}}$ levels and support a role for this current in regulating excitability and repetitive firing of CG cells (Shibata et al., 2000).

Two classes of auxiliary subunit proteins, Kv channelinteracting proteins (KChIP1-4) and dipeptidyl peptidase-like proteins (DPLPs) (DPP6 and DPP10) copurify from brain with Kv4 channels (An et al., 2000; Nadal et al., 2003; Jerng et al., 2004a; Rhodes et al., 2004; Marionneau et al., 2009). Heterologous expression studies show that the functional properties of native $I_{\mathrm{SA}}$ channels are closely matched by channels formed from the coexpression of Kv4 channels with DPLPs and KChIPs (Jerng et al., 2005, 2007; Amarillo et al., 2008; Maffie et al., 2009). Relatively little is known about the role auxiliary proteins play in

Received Nov. 5, 2009; revised April 27, 2010; accepted May 4, 2010.

This work was supported by National Institutes of Health Grants P01 NS37444, HD024064, GM090029, P3OHD024064, and T32GM008507. We thank Dr. Henry Jerng for his advice and critical review of this manuscript.

Correspondence should be addressed to Paul J. Pfaffinger, Department of Neuroscience, Baylor College of Medicine, One Baylor Plaza, Houston, TX 77030. E-mail: paulp@bcm.tmc.edu.

DOI:10.1523/JNEUROSCI.5489-09.2010

Copyright $\odot 2010$ the authors $\quad 0270-6474 / 10 / 308551-15 \$ 15.00 / 0$ regulating the electrophysiological properties of native neurons. To study the function of DPP6 in CG cells, we implemented an RNA interference (RNAi) strategy to selectively knock down DPP6 mRNA and thus disrupt DPP6 protein expression (Brummelkamp et al., 2002). By using lentiviral vectors to express the RNAi in CG cells, we can alter DPP6 expression in $>95 \%$ of neurons in culture. Given the homogeneity of CG cell cultures, this approach allows us to perform biophysical and protein biochemistry studies in the same system.

Loss of DPP6 from CG cells reduces $I_{\mathrm{SA}}$ peak conductance density and alters gating of the residual $I_{\mathrm{SA}}$. In both CG cells and hippocampal neurons, loss of DPP6 produces a dramatic reduction in multiple $I_{\mathrm{SA}}$ channel subunit protein levels. Currentclamp recordings from CG cells reveal changes in excitability produced by loss of DPP6. Although some of the changes in excitability are readily explained by changes in $I_{\mathrm{SA}}$ function, changes in input resistance and action potential rate of rise suggest additional effects on leak channels and voltage-gated $\mathrm{Na}^{+}$ channels that may reflect other regulatory functions of DPP6. Indeed, CG cells lacking Kv4.2 but possessing DPP6 have dramatically reduced $I_{\mathrm{SA}}$ but show no significant changes in input resistance or AP rate of rise. These combined effects suggest a role for DPP6 in sculpting the high-frequency excitability of CG cells and provided additional insights into the potential role of DPP6 in important human pathologies (Marshall et al., 2008; van Es et al., 2008; Alders et al., 2009).

\section{Materials and Methods}

RNAi vector construction and preparation. A set of mouse DPP6 (mDPP6) RNAi lentiviral vectors were screened for effects on mDPP6 expression in HEK cells, including vectors developed in the laboratory along with miRNA and short hairpin RNA (shRNA) vectors obtained from Open Biosystems. Initial screening was performed in HEK cells by testing for 
the suppression of a cotransfected pCMV-mDPP6 cDNA without affecting the expression of human or rat DPP6 constructs (supplemental Fig. 1, available at www.jneurosci.org as supplemental material). The RNAi expression cassette from the most efficient DPP6 RNAi (Open Biosystems; TRCN0000031425) was subcloned into a pLenti synapsin-eGFP vector to allow fluorescent tagging of infected neurons (Xue et al., 2008). Negative control lentiviral particles were derived from a lentiviral construct identical to mDPP6 RNAi pLenti construct, expressing enhanced green fluorescent protein (eGFP) under the control of a synapsin promoter, but with a nonspecific RNAi sequence in place of the mDPP6 RNAi target sequence. To validate the specificity of RNAi effects, we used the specificity of our RNAi for mDPP6 to construct a rescue vector that replaces the knocked down mDPP6 with rat DPP6a (rDPP6a) by cloning a CMVrDPP6a expression cassette into our pLenti-mDPP6 RNAi vector. To produce lentiviral particles from pLenti vectors, HEK cells were transfected with $6 \mu \mathrm{g}$ of pLenti, pVSV-G, and pDelta8.9 plasmids using calcium phosphate method (Lois et al., 2002; Mitta et al., 2005; Tiscornia et al., 2006). Sixty hours after transfection, HEK cell supernatants were collected and spun briefly for $5 \mathrm{~min}$ at $1000 \mathrm{rcf}$ to remove cellular debris. Viral supernatants were spun at 120,000 $\mathrm{rcf}$ in a swinging bucket rotor (SW28) in a Beckman Coulter ultracentrifuge through a sucrose cushion. Viral preparations from individual six-well plates were resuspended in $200 \mu \mathrm{l}$ of sterile HBSS and titrated on cultured CG cells by eGFP fluorescence. Typically, a viral titer sufficient to achieve $95 \%$ transduction efficiency was achieved with $25 \mu$ l of purified lentiviral preparation for control and mDPP6 RNAi and is designated $1 \times$. Because of the increased size of the proviral insert of the rescue construct, lentiviral preparations from this plasmid failed to achieve transduction efficiencies $>50 \%$. CG cultures were infected $1-2 \mathrm{~d}$ after culturing and left for 5-21 d before analysis.

Cell culture. HEK cells (American Type Culture Collection) were maintained in DMEM (Invitrogen) supplemented with 10\% fetal bovine serum (HyClone Laboratories) and penicillin/streptomycin (Invitrogen). For CG cell cultures, C57/B6J postnatal day 4 (P4) to P6 pups were killed per Baylor College of Medicine Center for Comparative Medicine animal use guidelines, and cerebella were isolated by dissection. Pooled cerebella were minced and placed in $0.25 \%$ trypsin in HBSS (Invitrogen) for $15 \mathrm{~min}$ at $30^{\circ} \mathrm{C}$. Cerebellar tissue was lightly triturated and spun at 500 rcf for 5 min, resuspended in HBSS with DNase I (Worthington Biochemicals), and spun at $500 \mathrm{rcf}$ for $5 \mathrm{~min}$. The tissue was then resuspended in Neurobasal A supplemented with B-27 (Invitrogen), penicillin/streptomycin (1 U/ml) (Invitrogen), GlutaMax (Invitrogen), and $20 \mathrm{~mm} \mathrm{KCl}$, and plated onto poly-D-lysine-treated $12 \mathrm{~mm}$ coverslips in 24-well plates. Neurons were maintained up to 3 weeks by $50 \%$ media replacement every $3 \mathrm{~d}$. Mouse hippocampal neurons were cultured from P1 pups and grown similarly to CG neurons, except without elevated $\mathrm{KCl}$.

Western blotting and densitometry. For Western blot analysis, cells were lysed in SDS-Laemmli sample buffer supplemented with protease inhibitor mixture (Sigma-Aldrich) and $100 \mathrm{~mm}$ dithiothreitol. Cells were harvested at 4,10 , and $14 \mathrm{~d}$ in vitro (DIV) to probe the effect of mDPP6 RNAi knockdown on DPP6 levels and at 10 DIV to probe the effect of mDPP6 RNAi on $I_{\mathrm{SA}}$ channel protein levels. Samples were briefly sonicated and spun to remove insoluble material, and then loaded onto SDS-PAGE gels. For most experiments, proteins were separated on SDS Tris-Cl 4-20\% gradient gels (Invitrogen) followed by overnight transfer onto activated polyvinylidene difluoride membranes (Millipore). Primary antibodies [rabbit anti-DPP6 (ab41811; Abcam); rabbit anti-Kv4.2 (5360; Millipore); rabbit anti-KChIP3/DREAM (sc-9142; Santa Cruz Biotechnology); mouse antiglyceraldehyde-3-phosphate dehydrogenase (GAPDH) (6C5; Advanced Immunochemical)] were used at 1:1000 dilution and detected by horseradish peroxidase-conjugated secondary antibodies (1:10,000; Pierce) using Pico or Femto ECL (Pierce). Western blot exposures were carefully adjusted to avoid saturation, scanned as 24-bit TIF files, and analyzed using OptiQuant 3.1 (PerkinElmer Life and Analytical Sciences). Western blot experiments were performed in triplicate; densitized signals were averaged and normalized to control signal (GAPDH).

Electrophysiological methods and data analysis. Electrophysiological recordings were performed on cultured CG cells infected with lentiviral vectors using both whole-cell voltage- and current-clamp configura- tions. Morphological identification of infected CG cells was performed using eGFP expression from the pLenti synapsin-eGFP expression cassette. Control recordings from uninfected CG cells were found to be indistinguishable from control lentivirus-infected neurons. Recording pipettes were made from borosilicate glass (TW150F-4; World Precision Instruments) using a Sutter P-97 puller (Sutter Instrument). Pipettes were pulled to resistances between 4 and $6 \mathrm{M} \Omega$ for voltage clamp and 6-10 M $\Omega$ for current clamp. Series resistance could typically be corrected by $>70 \%$. Data were collected using a AxoPatch 200B amplifier (Molecular Devices) controlled by a Dell microcomputer interfaced to recording equipment through a Digidata 1332 interface running pCLAMP, version 9, software (Molecular Devices). Electrophysiology data analysis was performed using Clampfit (Molecular Devices), WinWCP (University of Strathclyde, Glasgow, UK), and OriginPro (OriginLab). For whole-cell voltage-clamp recordings, pulled pipettes were backfilled with internal solution containing the following (in $\mathrm{mM}$ ): $120 \mathrm{~K}$-gluconate, $10 \mathrm{KCl}, 10$ HEPES, 10 BAPTA, $3 \mathrm{MgCl}_{2}$, 4 ATP, 0.4 GTP. To pharmacologically isolate $I_{\mathrm{SA}}$, the bath solution contained the following (in $\mathrm{mM}$ ): $85 \mathrm{NaCl}$, 40 tetraethylammonium (TEA)-Cl, $2.5 \mathrm{KCl}, 25 \mathrm{NaHCO}_{3}, 2 \mathrm{CaCl}_{2}, 1$ $\mathrm{MgCl}_{2}, 10$ glucose, 0.1 4-aminopyridine, 0.001 tetrodotoxin, $\mathrm{pH}$ 7.4, 305 $\mathrm{mOsml} \mathrm{L}{ }^{-1}$. Current clamp was performed with an internal solution containing reduced $\mathrm{Ca}^{2+}$ buffering (in mM: $120 \mathrm{~K}$-gluconate, $20 \mathrm{KCl}, 10$ HEPES, 0.2 EGTA, $2 \mathrm{MgCl}_{2}$, 4 ATP, 0.3 GTP, 14 phosphocreatine, $\mathrm{pH}$ 7.3). The bath solution for current-clamp recordings did not contain pharmacological blockers to isolate $I_{\mathrm{SA}}$ (in $\mathrm{mm}$ : $125 \mathrm{NaCl}, 2.5 \mathrm{KCl}, 25$ $\mathrm{NaHCO}_{3}, 2 \mathrm{CaCl}_{2}, 1 \mathrm{MgCl}_{2}, 10$ glucose). A subset of voltage-clamp recordings was performed with our current-clamp solutions to determine the potential effects of mDPP 6 knockdown on other currents in addition to $I_{\mathrm{SA}}$. Because of increased $\mathrm{Na}^{+}$current amplitude at $>15 \mathrm{~d}$ in culture, adequate voltage-clamp control was not possible in this solution, so recordings in a reversed $\mathrm{Na}^{+}$gradient were also performed to characterize $\mathrm{Na}^{+}$current amplitudes at these later times (Osorio et al., 2005). Control experiments verified that conductance density measurements for $\mathrm{Na}^{+}$ channels at $10 \mathrm{~d}$ in culture are similar in both solutions. A 95\% $\mathrm{O}_{2} / 5 \%$ $\mathrm{CO}_{2}$-aerated bath solution at $23^{\circ} \mathrm{C}$ was perfused over CG cells cultured on coverslips at a constant rate of $3 \mathrm{ml} \mathrm{min}^{-1}$. Primarily because of the gluconate anion in our internal solution, a junction potential of approximately $-14 \mathrm{mV}$ is present in our recordings; therefore, our reported potentials are adjusted by $-14 \mathrm{mV}$ from the applied command potentials or recorded current-clamp membrane potentials (Barry, 1994).

$I_{\mathrm{SA}}$ was studied after additional isolation from any residual current remaining after pharmacological block by subtracting non-inactivating currents recorded using a $500 \mathrm{~ms}$ prepulse potential of $-34 \mathrm{mV}$ from total outward current using a prepulse potential of $-114 \mathrm{mV}$. $I_{\mathrm{SA}}$ activation was examined by stepping to voltages from -74 to $+66 \mathrm{mV}$ for 250 ms. Peak current amplitude was measured and converted to peak conductance, and normalized peak conductance values were plotted versus the eliciting voltage step and fit with a single Boltzmann function. For inactivation, $I_{\mathrm{SA}}$ was recorded after a $500 \mathrm{~ms}$ prepulse that ranged from -124 to $-34 \mathrm{mV}$. Peak current was measured during a test pulse to -24 $\mathrm{mV}$ after subtraction of any non-inactivating current that remained after the most positive prepulse potentials were applied. Normalized peak current was plotted against the prepulse voltage step; and these data were fit with a single Boltzmann function. For inactivation kinetics in control cells, one to two exponentials were needed depending on the test potential used. Typically, the faster component was $80-100 \%$ of the total decay in control cells, with the slower component increasing as the test potential was made more positive. In mDPP6 RNAi-treated cells, the current decay was well fit with a single exponential. It is possible that an additional slower inactivation kinetic is present in mDPP6 RNAi-treated cells; however, because of small current amplitudes and residual noise in the traces, only a single exponential fit could be justified. To directly compare control with mDPP6 RNAi-treated cells, only the dominant fastest inactivation kinetic was used. To examine $I_{\mathrm{SA}}$ recovery from inactivation, we used a two-pulse protocol that delivered a $250 \mathrm{~ms}$ prepulse to $+26 \mathrm{mV}$ to inactivate $I_{\mathrm{SA}}$ channels, followed by a variable recovery interval at $-114 \mathrm{mV}$ and a second test pulse to $+26 \mathrm{mV}$ to elicit recovered $I_{\mathrm{SA}}$. The recovery from inactivation was measured as the fraction amplitude 
of the current in the second pulse with $0 \%$ recovery set by the current remaining at the end of the first pulse and $100 \%$ recovery set by the peak amplitude of the current in the first pulse. Fractional recovery data were plotted against the variable recovery interval and fit with a single exponential function.

Action potential waveform properties were analyzed by phase plot analysis of spikes (Bean, 2007). Waveform derivatives were determined using five-point second-order polynomial smoothing using Origin. Threshold was measured by linear extrapolation of the initial rising phase of the phase plot to its intersection with the baseline noise. CG cells show distinct changes in firing properties as they mature in culture (Osorio et al., 2005; Okazawa et al., 2009). In our recordings, significant spiking begins by $7 \mathrm{~d}$ in culture and matures to a strong repetitive firing pattern between days 10 and 15 in culture. We therefore segregated our analyses of effects on firing properties into two groups (DIV $\leq 10$, recordings performed 7-10 DIV; DIV $\geq 15$, recordings performed 15-21 DIV). Important changes at later time points include the following: biphasic rising phase of phase plot indicative of a mature axon hillock, all cells repetitively firing, and much steeper rising and falling velocities for actions potentials (Osorio et al., 2005; Bean, 2007; Diwakar et al., 2009). Only first spikes were used for all phase plot analyses, except for CG cells recorded at later times in culture in which the first spike in the repetitive firing train was also analyzed. Repetitive firing typically began on the second spike generated, as discussed in the text.

Measured data values were found to be Gaussian distributed as examined by histogram analysis (example shown in Fig. $6 B$ ), and significance testing was performed using independent $t$ tests and one- or two-way ANOVAs, with a significant change set at the 0.05 level and indicated in bar graphs by an asterisk $\left.{ }^{*}\right)$.

NEURON computational modeling. A CG cell model was constructed using NEURON to examine the effects of changing $I_{\mathrm{SA}}$ on neuronal firing properties (Hines and Carnevale, 2001). For this work, a standard 10$\mu \mathrm{m}$-diameter single-compartment spherical model at $23^{\circ} \mathrm{C}$ was used for most simulations. For a subset of studies, we also examined a previously published multicompartment CG cell model to examine potential effects of the axon hillock on action potential waveform properties (Diwakar et al., 2009). Our voltage-clamp studies provide peak conductance density estimates for A-type current, $\mathrm{Na}^{+}$current, and non-inactivating voltagegated potassium currents in our neurons under both control and RNAi treatment conditions. A linear resting conductance, $G_{\text {leak }}$, was estimated for control and RNAi-treated CG cells models based on the observed input resistance under current clamp. To keep the model simple, yet consistent with our voltage clamp, we only modeled the following CG cell current components: for A-type current: slow and fast $I_{\mathrm{SA}}$, for changes in input resistance, a linear leak component; for $\mathrm{Na}^{+}$current: a single fast inactivating $\mathrm{Na}^{+}$channel; for $I_{\mathrm{K}}$ : a delayed rectifier potassium $(\mathrm{Kv})$ channel, a calcium-activated potassium (BK) channel, and a high voltage-gated calcium $[\mathrm{Ca}(\mathrm{HV})]$ channel to activate BK. Model parameters for $\mathrm{Na}, \mathrm{Kv}, \mathrm{BK}$, and $\mathrm{Ca}(\mathrm{HV})$ channels were imported from a previously published NEURON model for CG cells (D'Angelo et al., 2001). $I_{\mathrm{SA}}$ was modeled using an $\mathrm{m}^{3} \mathrm{~h}$ HH-based model fit to our experimental data. Because inactivation is double exponential, we split the model into two $\mathrm{HH}$ models, $I_{\mathrm{SA} \text { (fast) }}$ and $I_{\mathrm{SA}(\text { slow) }}$, with identical activation parameters but different inactivation parameters to match the observed kinetics. Rates were calculated by the following: $k\left(E_{\mathrm{m}}\right)=k_{0} \exp \left(k_{\mathrm{v}}\left(E_{\mathrm{m}}-E_{\mathrm{JP}}\right)\right)$, where $k_{0}$ is the rate measured at $0 \mathrm{mV}, k_{\mathrm{v}}$ is the voltage dependence of the rate, and $E_{\mathrm{JP}}$ is the calculated junction potential shift of $-14 \mathrm{mV}$. Parameters used for $k_{0}$ and $k_{\mathrm{v}}$ are shown in Table 1 . Common maximum conductance values between the control and mDPP6 RNAi CG cells models shown in Figure 10 were as follows (in S/ $\mathrm{cm}^{2}$ ): Na, 0.018; Kv, 0.0003; BK, $0.0043 ; \mathrm{Ca}(\mathrm{HV}), 10^{-6}$. For control neurons, the A-current and leak maximum conductance values were as follows $\left(\right.$ in $\mathrm{S} / \mathrm{cm}^{2}$ ): $I_{\mathrm{SA} \text { (fast) }}, 0.003$; $I_{\mathrm{SA} \text { (slow) }}, 0.0005 ; I_{\text {leak }}, 0.00025$. For the mDPP6 RNAi neurons model shown in Figure 10, only the maximum conductance values were changed, as follows (in $\mathrm{S} / \mathrm{cm}^{2}$ ): $I_{\mathrm{SA} \text { (fast) }}, 0.0005 ; I_{\mathrm{SA} \text { (slow) }}, 3 \times 10^{-5} ; I_{\text {leak }}$, 0.00015 . Driving forces were calculated with $E_{\mathrm{Na}}=50 \mathrm{mV}, E_{\mathrm{K}}=-90$ $\mathrm{mV}$, and $\mathrm{Ca}_{(\mathrm{i})}=50 \mathrm{nM}, \mathrm{Ca}_{(\mathrm{o})}=2 \mathrm{~mm}$. $E_{\text {rest }}$ was set at $-84 \mathrm{mV}$ to match the junction potential corrected resting potential used in our currentclamp studies. Square-wave current injections in $10 \mathrm{pA}$ increments were
Table 1. Parameters used for $k_{0}$ and $k_{\mathrm{v}}$

\begin{tabular}{llc}
\hline Rate & $k_{0}\left(\mathrm{~ms}^{-1}\right)$ & $k_{\mathrm{v}}\left(\mathrm{mV}^{-1}\right)$ \\
\hline $\mathrm{m}$ (activation) & & \\
$\alpha$ & 1.51 & 0.0133 \\
$\beta$ & 0.1795 & -0.03144 \\
h-slow (inactivation) & & \\
$\alpha$ & $2.35 \times 10^{-9}$ & -0.21671 \\
$\beta$ & 0.0038 & -0.01143 \\
h-fast (inactivation) & & \\
$\alpha$ & $3.82 \times 10^{-8}$ & -0.20592 \\
$\beta$ & 0.0618 & -0.00064 \\
\hline
\end{tabular}

delivered to the models for 250 ms duration, and the effects on membrane potential were recorded. Slight adjustments of the final conductance parameters (given above) were performed to closely match the general firing properties of the representative control neuron shown in Figure 8 before reducing A-type current and leak conductance to model the mDPP6 RNAi neuron. Additional modeling studies were performed to determine the selective impact of shifts in leak conductance, $I_{\mathrm{SA}}$ amplitude, and $I_{\mathrm{SA}}$ kinetics (slowed by a factor of $2 \times$ ) or steady-state gating values (shifted by $+13 \mathrm{mV}$ ), as shown in supplemental Figure 2 (available at www.jneurosci.org as supplemental material). In addition, modeling with altered $\mathrm{Na}^{+}$current densities was used to determine the impact of changes in $\mathrm{Na}^{+}$conductance density on action potential waveform properties.

\section{Results}

\section{Knockdown of mouse DPP6 using mDPP6 RNAi lentiviral vector}

To study the functional role of DPP6 in native neurons, an RNAi strategy was used. Because multiple transcripts are expressed from different start sites in the DPP6 gene, only RNAi targets that are common for all mDPP6 isoforms were tested (Nadal et al., 2006; Takimoto et al., 2006; Jerng et al., 2009; Maffie et al., 2009). After screening 10 potential target sites for knockdown of heterologous mDPP6 expression in HEK cells, we selected a single shRNA for additional study in mouse CG cells (Fig. 1A). CG cells are ideal neurons for such studies since they are electrically compact, express high levels of $I_{\mathrm{SA}}$, and are so abundant that they can be cultured to near homogeneity (Levi et al., 1984; Korbo et al., 1993).

The mDPP6 shRNA was moved into pLenti-control, an $\mathrm{H} 1$ promoter shRNA-expressing lentiviral vector, that coexpresses eGFP from a synapsin promoter, to create the mDPP6 RNAi lentiviral vector (Xue et al., 2008). This shRNA was found to be selective for mDPP6, allowing the construction of a rescue pLenti vector by cloning a CMV-rDPP6a expression cassette into the mDPP6 RNAi lentiviral vector. Cotransfection of the rDPP6a rescue vector with hemagglutinin (HA)-tagged mDPP6 shows that HA-specific reactivity attributable to the expression of mDPP6 is lost when mDPP6 RNAi is expressed, but total DPP6 protein levels are maintained by the coexpressed rDPP6a (Fig. $1 B)$. Quantitation of knockdown specificity and rescue for these constructs, as well as other tested DPP6 constructs, are presented in supplemental Figure 1 (available at www.jneurosci.org as supplemental material).

The mDPP6 RNAi lentiviral vector was then tested on cultured mouse CG cells. At optimal titers, the synapsin eGFP expression cassette is expressed in $>95 \%$ of neurons, which maintain normal survival and morphology (Fig. 1C). Western blots on CG cell cultures infected with the mDPP6 RNAi lentiviral vector show a dramatic knockdown of mDPP6 protein compared to control, with the magnitude of DPP6 knockdown similar to that observed in HEK studies (Fig. 1D). 


\section{Effects of mDPP6 knockdown on CG} cell $I_{\mathrm{SA}}$

Whole-cell voltage-clamp studies on CG cells infected with the mDPP6 RNAi lentiviral vector were performed to determine whether knockdown of mDPP6 has any obvious effect on $I_{\mathrm{SA}}$. For all electrophysiology experiments, recordings were performed on eGFP-expressing neurons with expected CG cell morphologies using viral titers that produce a $50-80 \%$ infection rate. $I_{\mathrm{SA}}$ was selectively isolated from other native ionic currents using a combination of pharmacological and biophysical methods (see Materials and Methods).

In Figure $2 A$, we compare typical $I_{\mathrm{SA}}$ recorded from $C G$ cells infected with control and mDPP6 RNAi pLenti vectors. Reported potentials are corrected from the applied command potentials by a calculated $-14 \mathrm{mV}$ junction potential (Barry, 1994). In response to voltage steps from $-114 \mathrm{mV}$ to potentials between -54 and +46 mV, CG cells infected with control pLenti vectors show typical robust $I_{\mathrm{SA}}$ with properties matching Kv4 channelbased $I_{\mathrm{SA}}$ described previously in these neurons (Bardoni and Belluzzi, 1993; Shibata et al., 2000). At $7 \mathrm{~d}$ in culture, $I_{\mathrm{SA}}$ in control neurons has an average peak amplitude at $+6 \mathrm{mV}$ of $2350 \pm 256 \mathrm{pA}$ $(n=5)$ (Fig. $2 B$ ). In contrast, after DPP6 RNAi vector infection, there is a dramatic reduction in $I_{\mathrm{SA}}$ at all test potentials relative to control-infected neurons (Fig. $2 A$ ). Peak $I_{\mathrm{SA}}$ at $+6 \mathrm{mV}$ averages $358 \pm 60$ pA $(n=9)$ after mDPP6 RNAi treatment, a $>85 \%$ reduction in peak amplitude (Fig. $2 B$ ).

To ensure that the observed effects of mDPP6 RNAi are specific to the loss of DPP6, we tested for functional rescue by infection with the rDPP6 rescue vector. Coexpression of rDPP6a dramatically reverses the reduction in peak $I_{\mathrm{SA}}$ amplitude produced by mDPP6 RNAi (Fig. $2 A$ ). On average, we find that $C G$ cells infected with the rDPP6a rescue construct have a peak $I_{\mathrm{SA}}$ amplitude at $+6 \mathrm{mV}$ of $2303 \pm$ $214 \mathrm{pA}(n=8)$, similar to control neurons (Fig. $2 B$ ). Normally, CG cells express several different isoforms of DPP6, not just DPP6a (Nadal et al., 2006; Maffie et al., 2009). Rescue with rDPP6a alone produces appreciable differences in inactivation kinetics of $I_{\mathrm{SA}}$ relative to control (Fig. $2 A)$. Exponential fits of the fast component of $I_{\mathrm{SA}}$ decay reveals a significantly faster initial rate of decay for the rDPP6a rescue condition compared with controltreated neurons [at $+66 \mathrm{mV}$ : control $\tau_{\text {fast }}$, $10.77 \pm 1.1 \mathrm{~ms}(n=8) ; \operatorname{rDPP} 6 \mathrm{a} \tau_{\text {fast }}$, $7.77 \pm 0.4 \mathrm{~ms}(n=10)$; significantly dif-
A
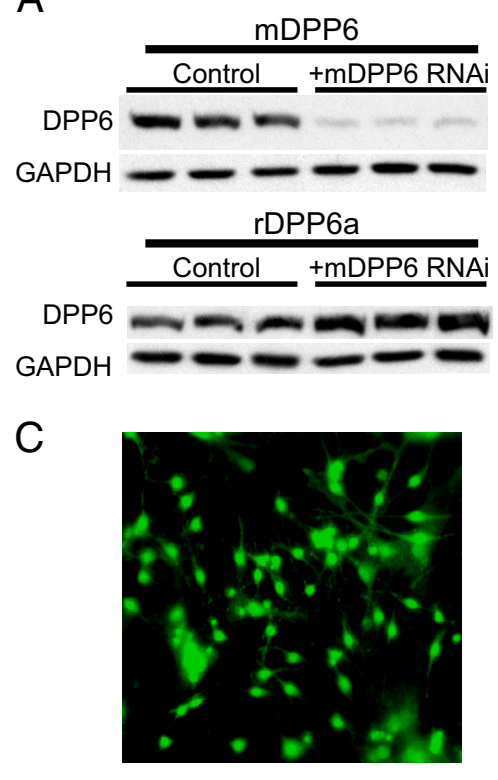

Granule Cell Culture
B

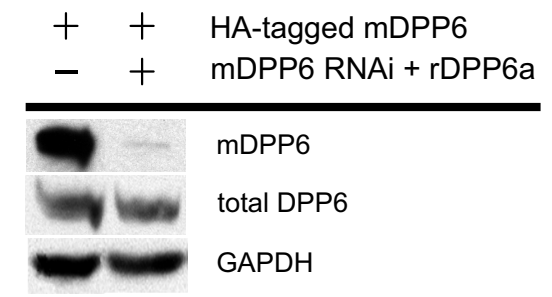

D

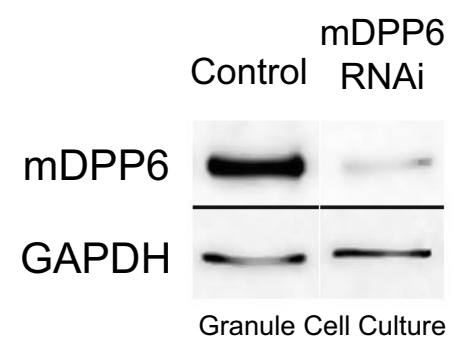

Figure 1. A mouse DPP6 lentiviral-based RNAi suppression and specific rescue system. $\boldsymbol{A}$, HEK cells were transfected with the indicated DPP6 expression vector, and then treated with control or mDPP6 RNAi vectors. Triplicate Western blots show that mDPP6 RNAi has a strong selective suppression of $\operatorname{mDPP} 6(n=9)$ with no effect on rDPP6a $(n=3)$. B , Specific rescue vector expressing rDPP6a along with mDPP6 RNAi was coexpressed with mouse HA-DPP6 in HEK cells. Western blots show that the rescue vector suppresses mDPP6, producing a loss of HA-tag immunoreactivity, and replaces it with a similar level of rat DPP6 expression ( $n=$ 3). C, CG cells were infected with lentiviral particles generated from the mDPP6 RNAi vector. At optimal dose, $>95 \%$ of CG cells are expressing eGFP indicative of infection with lentiviral vector and show the expected morphology even after 3 weeks in culture. D, Western blots on CG cells 10 DIV infected with mDPP6 RNAi lentivirus show that level of suppression of DPP6 protein in neurons is similar to that seen in control studies in HEK cells $(n=6)$.
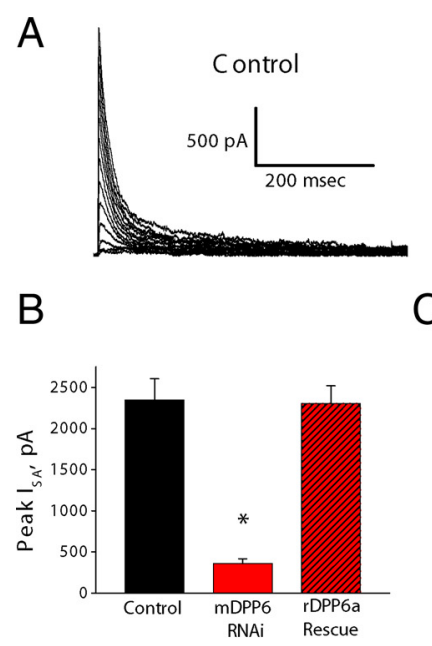

C

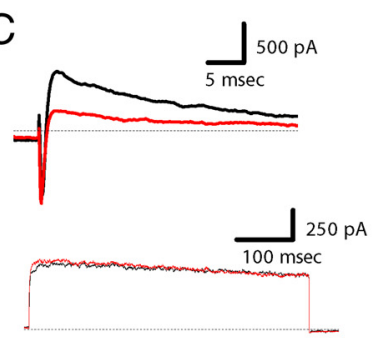

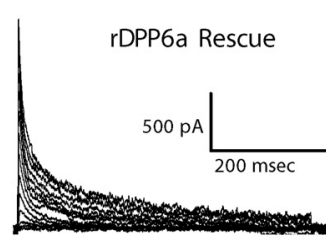

D

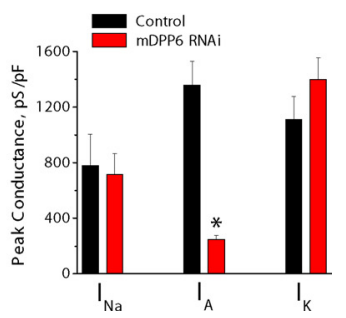

Figure 2. Suppression of $C G$ cell $I_{S A}$ by mDPP6 RNAi and specific rescue by coexpression of rat DPP6a. $\boldsymbol{A}$, Representative voltage-clamp recordings of $I_{S A}$ isolated from $C G$ cells after infection with indicated lentiviral vector. Infection with mDPP6 RNAi lentiviral vector strongly suppresses $I_{S A}$ and can be specifically rescued by coexpression of the rat DPP6a protein. $B$, Quantitation of the results shows that mDPP6 RNAi suppresses $I_{S A}$ by $>85 \%$ compared with control. This effect is reversed when the mDPP6 suppression is compensated by coexpression of rat DPP6a (control, $n=5 ; \operatorname{mDPP} 6 \mathrm{RNAi}, n=9$; rDPP6a rescue, $n=8$ ). C, Voltage clamp of total membrane currents without pharmacological blockers shows that mDPP6 RNAi (red) selectively suppresses the amplitude of the A-type current compared with control (black). Top, Use of variable prepulse to isolate inactivation sensitive inward Na currents $\left(I_{\mathrm{Na}}\right)$ and outward A-type current $\left(I_{\mathrm{A}}\right)$. Comparing control (black) with mDPP6 RNAi (red) shows no significant change in $I_{\mathrm{Na}}$ but a clear reduction in $I_{\mathrm{A}}$. Bottom, No significant changes in outward Kv currents $\left(I_{K}\right)$ isolated by a strong test pulse after a prepulse to $-34 \mathrm{mV}$ to inactivate $I_{\mathrm{Na}}$ and $I_{\mathrm{A}}$. D, Quantitation of results from recordings such as those shown in $\boldsymbol{C}$ for $I_{\mathrm{Na}}$ and $I_{\mathrm{A}}$ and the non-inactivating $I_{\mathrm{K}}$ current components in control and mDPP6 RNAi-treated CG cells. Comparison of peak conductance densities for these components reveals that a conductance underlying A-type current is selectively suppressed by mDPP6 RNAi (control, $n=7$; mDPP6 RNAi, $n=8$ ). Error bars indicate SEM. 
A

\section{Cerebellar Granule Cells}
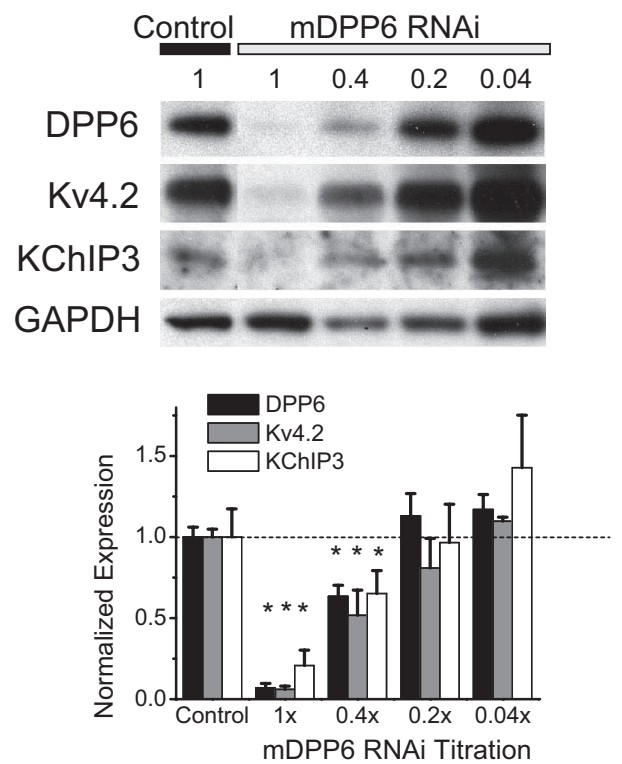

B
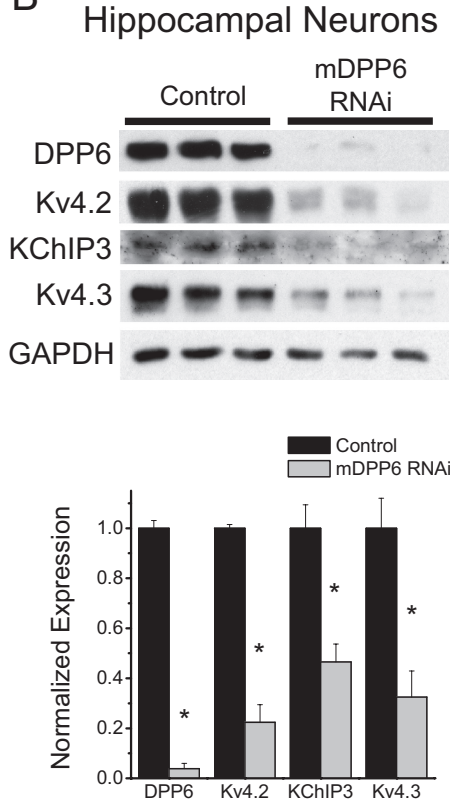

Figure 3. $I_{S A}$ channel proteins are reduced in neurons infected with mDPP6 RNAi expressing lentiviral vectors. $A$, CG cells were infected with a series of dilutions of purified virus to determine an optimal titer for mDPP6 suppression. A series of dilutions ( 0.4 , 0.2 , and $0.04 \times)$ of the highest titer $(1 \times)$ were tested by Western blot for the ability to suppress mDPP6 expression. Control granule cells $(1 \times)$ were infected with the same titer as mDPP6 RNAi-treated cells of the same label $(1 \times)$. Westerns at 10 DIV show that, along with DPP6, other protein components of the $I_{S A}$ channel complex (Kv4.2 and KChIP3) are specifically lost in a dosedependent manner. Quantitation of Western blots after normalization using GAPDH shows that at the optimal titer $>95 \%$ of DPP6 protein is lost from CG cells, with similar suppression of Kv4.2 and KChIP3. Shown are summary data from experiments performed in triplicate on three separate cultures. $\boldsymbol{B}$, Triplicate Western blots for mouse hippocampal neuron cultures infected with control and mDPP6 RNAi-expressing lentiviral vectors. Westerns for DPP6, Kv4.2, KChIP3, and Kv4.3 all show significant protein reductions after mDPP6 RNAi treatment. A control protein, GAPDH, is not sensitive to mDPP6 RNAi expression. Quantitation of Western blots after normalization to GAPDH signal shows a $>95 \%$ suppression of DPP6 and $55-80 \%$ loss of other $I_{\mathrm{SA}}$ associated proteins Summary data from experiments performed in triplicate on three separate cultures. Error bars indicate SEM.

ferent at $p=0.05]$. However, despite the faster initial activation of $I_{\mathrm{SA}}$ in $\mathrm{rDPP} 6 \mathrm{a}$-expressing CG cells, there is a significantly greater fraction of current left $50 \mathrm{~ms}$ after the depolarizing pulse is delivered. (After $50 \mathrm{~ms}$ at $+66 \mathrm{mV}$, the fraction of peak current remaining was as follows: control, $19.7 \pm 0.02 \%(n=8)$; rDPP6a, $30.2 \pm 0.02 \%(n=12)$; significantly different at $p=0.05$. $)$ These changes are consistent with the known effects of rDPP6a on Kv4 channels, suggesting that only rDPP6a subunits are present on the channel after rescue (Jerng et al., 2009). We therefore conclude that loss of $I_{\mathrm{SA}}$ in CG cells with mDPP6 RNAi treatment is a specific effect, and likely a direct consequence of the loss of DPP6 protein in these neurons.

To test whether mDPP6 RNAi reduces the amplitude of all currents or whether this effect is selective for $I_{\mathrm{SA}}$, a set of recordings was performed 9-11 DIV on control and mDPP6 RNAi lentivirus-infected CG cells without the pharmacological methods typically used to isolate $I_{\mathrm{SA}}$. For these studies, peak inward $\mathrm{Na}^{+}$currents $\left(I_{\mathrm{Na}}\right)$, total inactivating A-type potassium currents $\left(I_{\mathrm{A}}\right)$, and non-A-type voltage-gated potassium currents $\left(I_{\mathrm{K}}\right)$ were isolated by selective voltage protocols and compared between control and mDPP6 RNAi-infected CG cells. Figure 2C, top, shows the typical A-type and $\mathrm{Na}^{+}$currents activated in response to a test pulse to $-24 \mathrm{mV}$ after a prepulse to $-114 \mathrm{mV}$. A stronger depolarization to $+6 \mathrm{mV}$ after a more positive prepulse from $-34 \mathrm{mV}$ to inactivate A-type and $\mathrm{Na}^{+}$currents isolates the $I_{\mathrm{K}}$ component (Fig. 2C, bottom). Comparing control recordings (black) with recordings from CG cells treated with mDPP6 RNAi (red) reveals the primary impact of $\mathrm{mDPP6}$ RNAi is restricted to A-type potassium currents, as confirmed by comparison of summary data in Figure 2D.

\section{Effects of mDPP6 RNAi on $I_{\mathrm{SA}}$ channel proteins}

We next sought to better understand the biochemical basis underlying the loss of $I_{\mathrm{SA}}$ seen in these studies. Because DPP6 is only one auxiliary subunit of a proposed multiprotein $I_{\mathrm{SA}}$ channel complex, Western blot analysis was used to determine whether changes in other $I_{\mathrm{SA}}$ channel protein components could underlie the loss of $I_{\mathrm{SA}}$ in mDPP6 RNAi-treated neurons. In addition to DPP6, both Kv4.2 and KChIP3 are highly expressed in CG cells, coimmunoprecipitate as part of a macromolecular complex, and so are likely to be, along with DPP6, common subunits of $I_{\mathrm{SA}}$ channels (An et al., 2000; Xiong et al., 2004; Strassle et al., 2005). We therefore performed Western blots to examine the levels of DPP6, Kv4.2, and KChIP3 in CG cells infected with the mDPP6 RNAi vector (Fig. 3A). To establish a clear relationship between the magnitude of MDPP6 knockdown and any effects on other $I_{\mathrm{SA}}$ components, we examined the effect of different lentiviral vector titers. At 10 DIV, control and mDPP6 RNAi-infected CG cells cultures were solubilized, resolved by SDS-PAGE, and probed for mDPP6 protein levels. As expected, treatment of cultured CG cells with increasing doses of purified lentiviral mDPP6 RNAi vector produces a clear dose-dependent reduction in DPP6 protein (Fig. 3A). The maximal effect of mDPP6 RNAi treatment results in a $>95 \%$ loss of mDPP6 protein from the culture. Western blots against Kv4.2 $\alpha$-subunit and the KChIP3 $\beta$-subunit show that these proteins are lost in parallel with mDPP6 protein. The reduction in the other $I_{\mathrm{SA}}$ components appears to be a response to the loss of DPP6 protein, explaining how knockdown of DPP6 expression reduces $I_{\mathrm{SA}}$ amplitude in these neurons.

To test whether the regulation of $I_{\mathrm{SA}}$ protein levels is a general neuronal function of DPP6 or restricted to CG cells, we have performed biochemical studies to determine the effects of mDPP6 RNAi on mouse hippocampal neuron $I_{\mathrm{SA}}$ channel proteins (Fig. $3 B$ ). For these studies, primary dissociated hippocampal cultures were infected with control and mDPP6 RNAi lentiviral vectors and cultured for 1 week. As in cultured CG cells, at optimal titers we obtain $>95 \%$ infection of mouse hippocampal neurons with purified vector and are able to examine the effects of DPP6 knockdown on $I_{\mathrm{SA}}$ subunit protein levels by Western blot. Infection of hippocampal cultures with mDPP6 RNAi vectors produces a dramatic loss of DPP6 protein compared with cultures infected with control vector. We then examined the levels of $\mathrm{Kv} 4.2, \mathrm{Kv} 4.3$, and KChIP3 and found these proteins are also dramatically reduced in hippocampal neurons after loss of mDPP6 by RNAi (Fig. 3B). 
A Control

RNAi
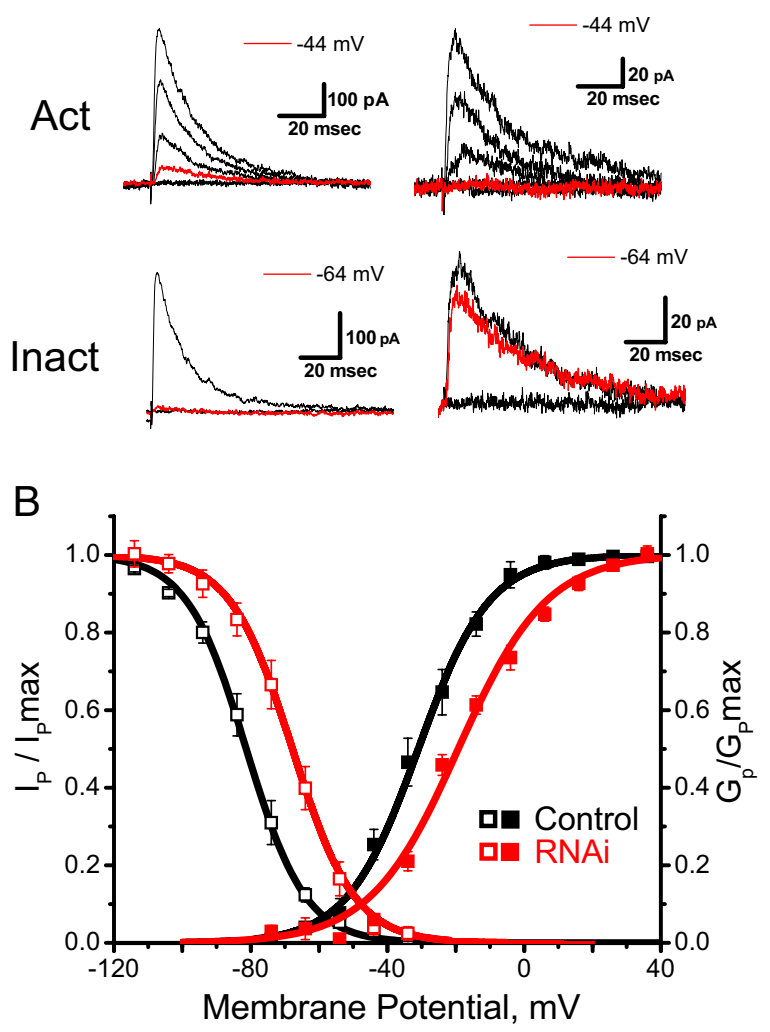

Figure 4. Steady-state inactivation curves and peak activation curves for $I_{S A}$ in control and mDPP6 RNAi-infected $C G$ cells. $A$, Representative traces for control and mDPP6 RNAi CG cells showing changes in voltage-dependent gating produced by loss of mDPP6. Activation shows currents in response to six voltage steps from -64 to $-4 \mathrm{mV}$. Highlighted trace from $-44 \mathrm{mV}$ shows clearly that $I_{\mathrm{SA}}$ in control cells activates at more negative potentials than in cells treated with mDPP6 RNAi. Inactivation shows test currents after prepulses to $-114,-64$, and $-34 \mathrm{mV}$. Intermediate level of inactivation produced by a pulse to $-64 \mathrm{mV}$ shows that control $/{ }_{S A}$ inactivates more completely at this potential than $I_{S A}$ in cells treated with mDPP6 RNAi. $B$, Summary results show that mDPP6 RNAi shifts gating curves to more positive potentials. Scatter plots show average values for activation and inactivation gating parameters for $I_{S A}$ recorded from control and mDPP6 RNAi-treated CG cells. Smooth curves show Boltzmann plots generated using midpoint and slope values obtained by the averages of fits to individual neurons. Curves verify that the average of the fits provides a good representation of the average data values at different voltages. Error bars indicate SEM.

\section{Residual $I_{S A}$ shows distinct changes in functional properties} from normal $I_{\mathrm{SA}}$

Our experiments achieve robust knockdown of DPP6 via RNAi and show that DPP6 plays an important role in setting the level of $I_{\mathrm{SA}}$ channel protein present in neurons, but does not show whether the normal DPP6 subunit stoichiometry is required to form functional $I_{\mathrm{SA}}$ channels in CG cells. To answer this question, we decided to test whether the functional properties of residual $I_{\mathrm{SA}}$ channels recorded in mDPP6 RNAi-treated CG cells are distinct from normal $I_{\mathrm{SA}}$ channels. Our prediction is that, if residual $I_{\mathrm{SA}}$ channels are constructed with a normal stoichiometry of DPP6 proteins, by incorporating residual DPP6 subunits that remain after RNAi, they will have functional properties that are similar to control. However, if the residual $I_{\mathrm{SA}}$ channels traffic to the surface with an absent or reduced DPP6 subunit composition, then they will display altered functional properties similar to Kv4 channels expressed in heterologous cells without DPP6 (Jerng et al., 2005, 2009; Amarillo et al., 2008).
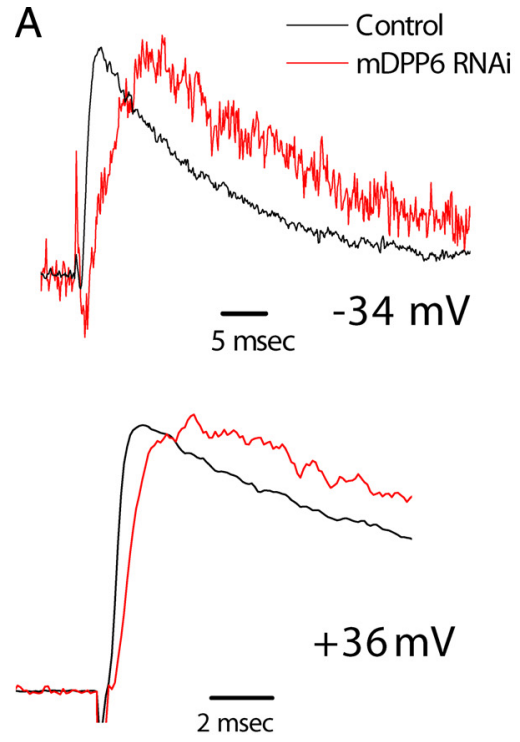

B

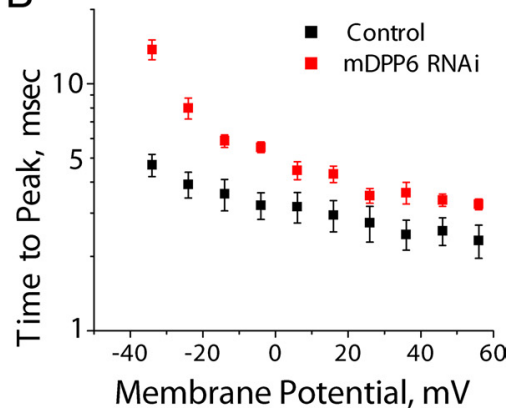

Figure 5. Residual $I_{S A}$ after mDPP6 RNAi suppression of DPP6 shows slowed activation kinetics. $A$, Peak normalized currents for $I_{S A}$ in control and mDPP6 RNAi-treated $C G$ cells in response to voltage steps to the indicated potentials are shown. At both small and large depolarizations, the rate of rise is slower after loss of DPP6. B, Cumulative data showing that time to reach peak current is slower for $I_{S A}$ at all potentials after suppression of DPP6 (control, $n=5$; mDPP6 RNAi $n=8$ ). Two-way ANOVA shows that time to peak is significantly slower for mDPP6 RNAi-treated CG cells compared with control. Error bars indicate SEM.

Careful isolation of the residual $I_{\mathrm{SA}}$ in mDPP6 RNAi-treated CG cells reveals that it is similar but functionally distinct from normal $I_{\mathrm{SA}}$. Figure $4 \mathrm{~A}$ shows representative traces highlighting the differences in channel activation and inactivation gating for control $I_{\mathrm{SA}}$ compared with the residual current after mDPP6 RNAi treatment. If the membrane potential is stepped to -44 $\mathrm{mV}$ to study channel activation gating, significantly greater activation of $I_{\mathrm{SA}}$ is seen in control cells compared with mDPP6 RNAitreated CG cells. For inactivation, a prepulse to $-64 \mathrm{mV}$ inactivates much more $I_{\mathrm{SA}}$ in control compared with mDPP6 RNAi-treated CG cells. Summary data for these analyses are shown in Figure $4 \mathrm{~B}$. Plots show the averaged data for control and mDPP6 RNAi-treated $I_{\mathrm{SA}}$ recordings at different test potentials. Individual activation and inactivation fits were performed for each cell and the results were averaged to obtain average activation midpoints and slopes. These group average fits were used to generate the continuous Boltzmann curves shown in solid lines. Summary values used in the plots are as follows: inactivation: midpoint, control: $-81.3 \pm 2.3 \mathrm{mV}(n=9)$; mDPP6 RNAi: $-67.8 \pm 2.4 \mathrm{mV}(n=13)$; slope, control: $-8.7 \pm 0.6 \mathrm{mV}(n=9)$; mDPP6 RNAi: $-9.1 \pm 0.7 \mathrm{mV}(n=13)$; activation: midpoint, control: $-31 \pm 2.6 \mathrm{mV}(n=9)$; RNAi: $-19.2 \pm 1.4 \mathrm{mV}(n=13)$; slope, control: $10.4 \pm 0.6 \mathrm{mV}(n=9)$; mDPP6 RNAi: $13.0 \pm 0.8$ 

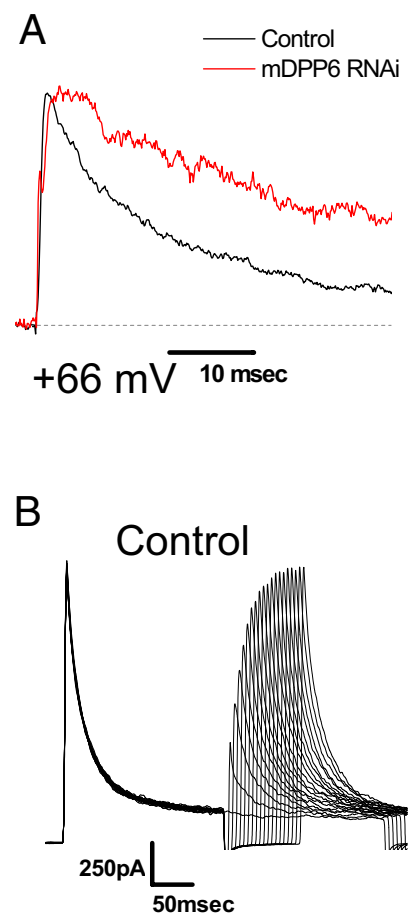
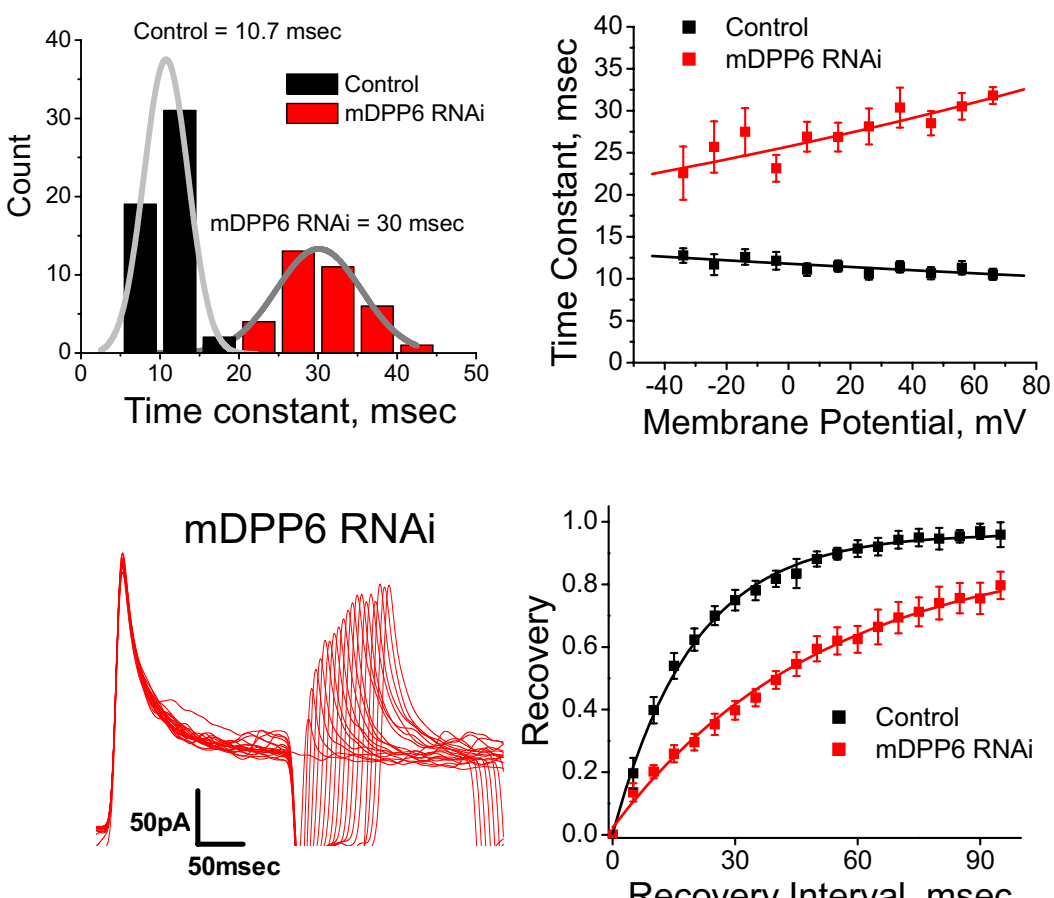

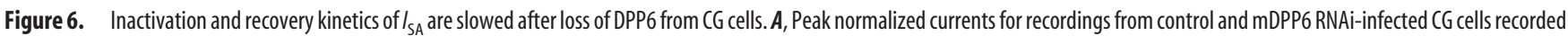
at a test potential of $+66 \mathrm{mV}$ show slower decay kinetics after suppression of DPP6. Histogram of all inactivation time constants for fits measured from currents evoked in response to voltage steps between +46 and $+66 \mathrm{mV}$. Control and mDPP6 RNAi inactivation time constants separate into two distinct distributions with loss of DPP6 slowing inactivation by approximately three times. SA $_{\text {S }}$ inactivation time constant shows an altered voltage dependence after suppression of DPP6. In control CG cells $(n=9)$, inactivation time constant accelerates as the test potential is made more positive. After infection with mDPP6 RNAi $(n=13)$, inactivation time constant slows as the test potential is made more positive. Time constants are significantly slower at all potentials after mDPP6 RNAi treatment by ANOVA. B, Recovery from inactivation for $I_{S A}$ is slower after suppression of DPP6 by RNAi. Currents for control and mDPP6 RNAi-infected neurons recorded using a two-pulse recovery protocol show that the recovery time is longer for $I_{S A}$ in the second pulse after $(G$ cells have been treated with mDPP6 RNAi. Summary recovery curves show recovery from inactivation is approximately three times longer after suppression of DPP6 [control $\tau, 19.9 \pm 2.2 \mathrm{~ms}(n=4)$; DPP6 RNAi $\tau, 62.0 \pm 12.6 \mathrm{~ms}(n=8)$; $p<0.05$ by $t$ test]. Error bars indicate SEM.

$\mathrm{mV}(n=13)$. For both activation and inactivation, there is a statistically significant rightward shift in gating midpoints of $12-13 \mathrm{mV}$. The slope of the fitted curve that describes the voltage dependence of steady-state inactivation was similar in both conditions, but slightly shallower, and the difference was statistically significant for the curve that describes the voltage dependence of steady-state activation.

In heterologous expression studies, the dominant effect of DPP6 on Kv4 channel-gating properties is a dramatic acceleration in gating kinetics. If the residual $I_{\mathrm{SA}}$ channels recorded after RNAi suppression of DPP6 lack normal levels of DPP6 protein, previous heterologous expression studies would predict that the kinetic properties of these channels should be slowed (Nadal et al., 2003; Dougherty and Covarrubias, 2006; Jerng et al., 2009; Maffie et al., 2009). We therefore compared the activation gating properties of $I_{\mathrm{SA}}$ channels between control and DPP6 RNAitreated CG cells. As shown in normalized and overlaid traces in Figure $5 \mathrm{~A}$, at $-34 \mathrm{mV}$ time to peak was significantly increased in DPP6 RNAi-treated CG cells compared with control $\left[I_{\mathrm{SA}}\right.$ time to peak, control, $4.7 \pm 0.5 \mathrm{~ms}(n=5)$; RNAi, $13.8 \pm 1.3 \mathrm{~ms}(n=8)]$. Although activation gating for $I_{\mathrm{SA}}$ in both control and mDPP6 RNAi-treated CG cells accelerates as the test potential becomes more positive, the relatively slower activation gating in MDPP6 RNAi-treated neurons is present at all potentials (Fig. $5 B$ ).

We next examined the effects of DPP6 RNAi on $I_{\mathrm{SA}}$ inactivation kinetics. Normalization of $I_{\mathrm{SA}}$ recorded from control and mDPP6 RNAi-treated CG cells at a test potential of $+66 \mathrm{mV}$ clearly shows that inactivation kinetics are slowed after mDPP6 RNAi treatment (Fig. 6A, left). To quantitatively compare inac- tivation kinetics, we performed exponential fitting of $I_{\mathrm{SA}}$ decay and compared the time constants between control and MDPP6 RNAi-treated CG cells. A complication in this approach is that $I_{\mathrm{SA}}$ decay in control CG cells becomes increasingly double exponential as test potentials are made more positive. In contrast, in mDPP6 RNAi-treated CG cells, $I_{\mathrm{SA}}$ decay at all potentials was well fit by a single-exponential decay. Given that the fastest kinetic component of current decay in control CG cells is responsible for $>80 \%$ of the inactivation at all potentials tested, we focused on comparing this kinetic component between control and DPP6 RNAi-treated CG cells. In Figure $6 A$, center, we constructed a histogram of all inactivation time constants measured from control and mDPP6 RNAi recordings at test potentials greater than $+26 \mathrm{mV}$. It is clear from this plot that measurements from control and mDPP6 RNAi-treated cells fall in two distinct Gaussian distributions, in which the mean for inactivation decay in mDPP6 RNAi-treated cells is threefold slower than in control cells. If we examine the voltage dependence for inactivation in the two populations, an additional difference becomes apparent. $I_{\mathrm{SA}}$ in CG cells infected with mDPP6 RNAi shows a distinct voltage dependence for inactivation in which the measured time constant becomes slower as the depolarization is made more positive (Fig. $6 \mathrm{~A}$, right). In contrast, control $I_{\mathrm{SA}}$ decay becomes faster as the test potential is made more positive. The accelerating inactivation kinetics of control $I_{\mathrm{SA}}$ in CG cells is thought to be attributable to an N-type mechanism provided by native expression of the isoform DPP6a. After DPP6 RNAi treatment, decelerating voltagedependent inactivation kinetics is expected for Kv4 channels 
coassembled with KChIP proteins that subsequently inactivate using the closedstate-dependent mechanism (Jerng et al., 2009).

In heterologous cells, in addition to accelerating activation and inactivation gating, DPP6 also accelerates recovery from inactivation for Kv4.2 channels (Nadal et al., 2003; Jerng et al., 2005, 2009; Amarillo et al., 2008). We therefore tested whether residual $I_{\mathrm{SA}}$ after DPP6 RNAi treatment shows a slowing in recovery from inactivation compared with control $I_{\mathrm{SA}}$. Recovery from inactivation was measured using a two-pulse protocol, and fractional recovery plotted against the duration of the recovery interval at $-114 \mathrm{mV}$ (Fig. 6B). Current traces comparing $I_{\mathrm{SA}}$ recovery in control and mDPPA RNAi-treated CG cells show that longer time intervals are needed to get the same level of recovery after mDPP6 RNAi treatment. Singleexponential fits to the summary data demonstrate a statistically significant, nearly threefold slowing in recovery from inactivation for mDPP6 RNAitreated CG cells relative to control (Fig. 6B) [inactivation recovery: control $\tau=$ $19.9 \pm 2.2 \mathrm{~ms}(n=4)$; DPP6 RNAi $\tau=$ $62.0 \pm 12.6 \mathrm{~ms}(n=8)]$.

\section{Effects of DPP6 RNAi on CG cell excitability}

Our voltage-clamp studies show that loss of DPP6 has a large effect on $I_{\mathrm{SA}}$, reducing the amplitude of the current and altering the gating properties of the residual $I_{\mathrm{SA}}$. Based on previous studies, we predict that such changes in native $I_{\mathrm{SA}}$ should alter CG cell excitability (Shibata et al., 2000; Yuan et al., 2005). Preliminary recordings showed that CG cells in culture begin firing action potentials consistently by 1 week in culture and firing properties continue to change over the next couple of weeks. By 2 weeks in culture, almost $100 \%$ of control CG cells demonstrate strong repetitive firing properties. We have therefore split our analyses of firing properties into two populations based on the number of DIV: young neurons, DIV $\leq 10$, and more mature neurons, DIV $\geq 15$. For this study, our analyses have focused on major changes in the firing properties of CG cells that result from the loss of mDPP6 protein by RNAi.

Treatment with mDPP6 RNAi was found to have no significant impact on resting membrane potential [control $V_{\text {rest }}=$ $-69.3 \pm 5.8 \mathrm{mV}(n=8)$; mDPP6 RNAi $V_{\text {rest }}=-66.3 \pm 4.7 \mathrm{mV}$ $(n=9)$ ] or cell capacitance $\left[\right.$ control $C_{\mathrm{M}}=5.81 \pm 0.28 \mathrm{pF}(n=8)$; mDPP6 RNAi $\left.C_{\mathrm{M}}=4.94 \pm 0.31 \mathrm{pF}(n=9)\right]$. However, the CG cell input resistance was significantly higher after mDPP6 RNAi treatment compared with control [control $R_{\text {input }}=1.1 \pm 0.1 \mathrm{G} \Omega$ $(n=8)$; mDPP6 RNAi $\left.R_{\text {input }}=2.0 \pm 0.2 \mathrm{G} \Omega(n=9)\right]$. Given the combination of gating curve shifts and changes in peak $I_{\mathrm{SA}}$ amplitude produced by mDPP6 RNAi (Figs. $2 A, 4 B$ ), we were interested in determining whether changes in the "window" current produced by $I_{\mathrm{SA}}$ at rest (Yuan et al., 2005; Kim et al., 2008) are responsible for the observed changes in input resistance. Both NEURON modeling and calculations based on steady-state gating values suggest that, although significant changes in $I_{\mathrm{SA}}$ win-

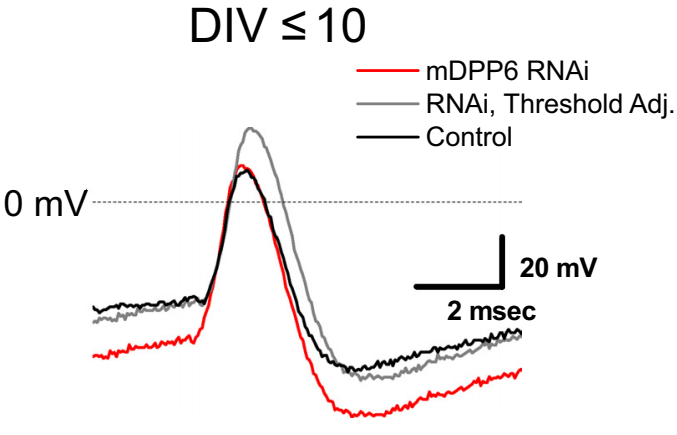

DIV $\leq 10$ (the threshold current injection show that control $\mathrm{CG}$ ells have a significant delay before firing the first spike. After suppression of DPP6, the delay is dramatically reduced and the CG cells fire during the initial depolarization.

dow currents occur, they are likely responsible for only $\sim 10$ $20 \%$ of the observed change in input resistance. In addition, the $I-V$ curve for $40 \mathrm{mV}$ around rest is linear under both the control and mDPP6 RNAi treatment conditions [linear correlation coefficient: control, $0.96 \pm 0.01(n=8) ; \operatorname{mDPP} 6 \mathrm{RNAi}, 0.97 \pm 0.01$ $(n=9)$; not significantly different at $p=0.05$ level $]$, suggesting that linear leak channels, rather than $I_{\mathrm{SA}}$, are primarily responsible for regulating the resting input resistance under both conditions. Together, these results suggest that loss of DPP6 has an effect on resting leak channels that is independent of its effects on $I_{\mathrm{SA}}$.

We examined the firing properties of control and mDPP6 RNAi-treated CG cells at $10 \mathrm{~d}$ or less in culture. For these studies, all neurons were held at a constant resting potential of $-84 \mathrm{mV}$ and excited by $250 \mathrm{~ms}$ constant current injections of varying amplitudes. At DIV $\leq 10$ in culture, loss of DPP6 dramatically increases the likelihood of firing a spike in response to a given current injection. In addition to the higher input resistance, mDPP6 RNAi-treated neurons also show a significantly lower threshold potential for firing spikes [control threshold, $-34.1 \pm 2.3$ $\mathrm{mV}(n=8)$; mDPP6 RNAi threshold, $-50.1 \pm 1.5 \mathrm{mV}(n=9)]$. Combined with the increased input resistance, there is a 2.4 -fold reduction in the minimum current injection required to reach threshold after mDPP6 RNAi treatment [control threshold current, $54 \pm 3.7 \mathrm{pA}(n=8)$; mDPP6 RNAi threshold current, $22.85 \pm 3.6 \mathrm{pA}(n=9)]$. Comparing the waveforms for the first spikes in control and mDPP6 RNA-treated CG cells, we see the clear shift in threshold potential (Figure 7A). If mDPP6 RNAi spikes are shifted to adjust for the difference in threshold, we can see that the spikes are slightly larger on average with similarly sized afterhyperpolarizations (AHPs). 


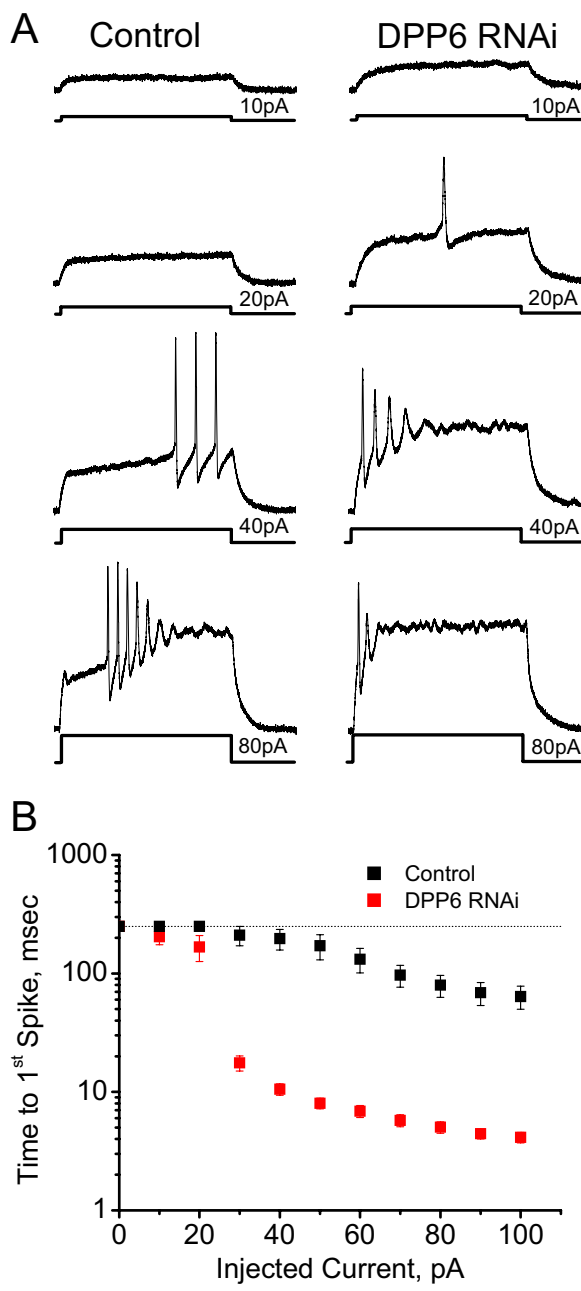

Figure 8. Control and mDPP6 RNAi-treated CG cells show distinctive changes in firing properties as sustained current injections are increased in amplitude. Shown are recordings from control and mDPP6 RNAi-expressing CG cells after $10 \mathrm{~d}$ or less in culture. $\boldsymbol{A}$, Control $\mathrm{CG}$ cells require higher current injections to reach threshold and maintain a significant delay before firing the first spike at all current amplitudes. CG cells infected with mDPP6 RNAi fire at lower current injections and the delay to first spike gets dramatically shorter as the amplitude of the current injection increases. $\boldsymbol{B}$, Summary data show that the time to first spike is dramatically shortened with increasing current injections after suppression of mDPP6. The dotted line at 250 $\mathrm{ms}$ indicates the maximum duration of the current injection, and thus values at this level indicate a failure to fire a spike (control, $n=8 ; \mathrm{mDPP} 6 \mathrm{RNAi}, n=9$ ). Differences are significant for all current injections above threshold. Error bars indicate SEM.

Another important difference at this time in culture is that mDPP6 RNAi-treated CG cells fire spikes much sooner during a superthreshold current injection than do control neurons. Figure $7 B$ compares firing properties of control and mDPP6 RNAitreated CG cells in response to current injections $10 \mathrm{pA}$ above threshold. Time to first spike summary data show a clear reduction in spike latency after mDPP6 RNAi treatment compared with control CG cells [control latency, $175.6 \pm 12.9 \mathrm{~ms}(n=8)$; mDPP6 RNAi latency, $54.2 \pm 17.4 \mathrm{mV}(n=9)]$. A second difference that can be observed in the spike latency representative data (Fig. $7 B$ ) is a stronger tendency for control CG cells, compared with mDPP6 RNAi-treated neurons, to fire repetitive spikes even though they require longer, stronger current injections to reach threshold. The tendency for control cells to fire repetitively increases with increased time in culture. The differences in time to first spike for control and mDPP6 RNAi-treated CG cells are maintained across a wide range of current injections (Fig. $8 A$ ). In
mDPP6 RNAi-treated CG cells, spikes fire within $20 \mathrm{~ms}$ of the start of the current injection as soon as current injection strength is as much as $10 \mathrm{pA}$ above threshold (Fig. $8 \mathrm{~B}$ ). In contrast, the control neurons at this time in culture never reach such short first spike latency even with the largest current injections.

Control recordings of CG cells at later time points in culture ( $15 \mathrm{~d}$ in culture and later) show a characteristic pattern of firing changes as the current injection strength is increased. At low current injections, CG cells typically show a delay to first spike followed by a sustained train of firing, similar to what is seen at stronger current injections in CG cells earlier in culture. A change occurs, however, with stronger current injections, in which most neurons fire a spike during the initial depolarization, which is followed by a silent period before a second phase of sustained firing begins (Fig. 9A). With even stronger current injections, the silent period shortens until eventually a continuous train of spikes is fired. Almost all control CG cell recordings show strong repetitive firing, with $>75 \%$ showing a significant lag time before the sustained firing phase begins.

For CG cells treated with MDPP6 RNAi, the results are quite different at DIV $\geq 15$. With mDPP6 RNAi treatment, CG cells did not fire repetitively. Instead, they consistently fired a single action potential in response to the initial current injection, but then were silent during the remaining $250 \mathrm{~ms}$ of the current injection, regardless of the amplitude of the current injection (Fig. 9A). To determine whether these effects are specifically related to the loss of DPP6, we compared these results with those obtained after rescue of mDPP6 RNAi by coexpression of rDPP6a. Expression of $\mathrm{rDPP} 6 \mathrm{a}$ rescues the repetitive firing of CG cells (Fig. 9A) [average number of spikes during a $250 \mathrm{~ms}$ current injection: control, $10.2 \pm 2.7(n=9)$; mDPP6 RNAi, $1 \pm 0.0(n=6) ;$ rDPP6a rescue, $6.9 \pm 1.3(n=10)$; control and rDPP6a rescue are not significantly different, but both are significantly different from mDPP6 RNAi at the $p=0.05$ level]. Like control neurons, CG cells rescued with $\mathrm{rDPP} 6 \mathrm{a}$ also show a characteristic gap between the initial spike and the sustained phase of firing.

We next examined the waveforms for the initial spikes to determine whether there are characteristic differences between control, mDPP6 RNAi-treated, and rDPP6a-rescued CG cells (Fig. $9 B$ ). The results demonstrate a striking difference in the action potential properties of these different neurons. At these later times in culture, the spikes produced by mDPP6 RNAi-treated neurons no longer have a more negative threshold than control and initiate from a similar or more positive potential than control or rDPP6a rescue CG cell action potentials. Interestingly, the AHPs are very different for mDPP6 RNAi-treated neurons compared with control. A distinctive fast AHP component is present in control, clearly missing in mDPP6 RNAi-treated neurons but rescued by $\mathrm{rDPP} 6 \mathrm{a}$ expression, suggesting that $I_{\mathrm{SA}}$ is responsible for this fast AHP (Fig. 9B). This difference in AHP was not apparent at $10 \mathrm{DIV}$; however, at this time in culture, spikes in control CG cells only occur after a prolonged depolarized plateau phase (Fig. 8A). We therefore compared the AHP shape at later times in culture for the first plateau spikes in control CG cells with the initial mDPP6 RNAi-treated CG cell spikes (Fig. 9B). The results show that, with increased time in culture, the control plateau spike AHPs are not significantly different from mDPP6 RNAi-treated CG cells, but are very different from the initial spike. This result suggests that there is likely significant inactivation of $I_{\mathrm{SA}}$ during plateau phase at all times in culture, and this effect can mask a role for $I_{\mathrm{SA}}$ in driving spike repolarization and AHP shape. Summary data comparing most negative AHP potential recorded under different conditions are as follows: control 
AHP, $-78.2 \pm 1.9 \mathrm{mV}(n=7) ; \mathrm{mDPP} 6$ RNAi AHP, $-54.3 \pm 6.6 \mathrm{mV}(n=3)$; control plateau AHP, $-56.1 \pm 6.3 \mathrm{mV}$ $(n=7)$; rDPP6a rescue AHP, $-70.25 \pm$ $4.7 \mathrm{mV}(n=5)$; mDPP6 RNAi and control plateau AHP amplitude are not significantly different, but both are significantly different from initial control AHP and rDPP6a rescue conditions.

Finally, we examined the action potential kinetics of initial spikes. Summary results from phase plot analysis (Fig. 9C) reveal that both the rising and falling phases of the spikes are slower in MDPP6 RNAi-treated neurons than in control or rDPP6a-rescued CG cells. In fact, the mDPP6 RNAi-treated CG cells appear to have a failure to develop rapid spike kinetics since their action potential kinetics are similar to those observed in both control and mDPP6 RNAi-treated cells at earlier times in culture.

Although a slowing of the falling phase of the action potential after mDPP6 RNAi treatment is expected given the role of $I_{\mathrm{SA}}$ in driving spike repolarization and forming an early AHP component, the slowing of the rising phase is not easily explained. The rising phase of an action potential is typically regulated by $\mathrm{Na}^{+}$channels, with a higher density or faster activation producing a faster action potential rising phase. We therefore tested whether mDPP6 RNAi treatment has a significant impact on $\mathrm{Na}^{+}$ current amplitude at $15 \mathrm{~d}$ or later in culture (Fig. 9D). Unlike results from earlier time points in culture, the $\mathrm{Na}^{+}$current density appears to be significantly reduced at later times in culture after mDPP6 RNAi treatment.

\section{Modeling of neuronal firing with and without mDPP6 RNAi}

To examine the underlying mechanisms producing the changes in firing properties produced by mDPP6 RNAi treatment, we constructed electrophysiological models of CG cells using NEURON (Hines and Carnevale, 2001). Our initial modeling studies were on CG cells at earlier times in culture. Conductance densities in a single-compartment CG cell model were adjusted to reflect the current amplitudes recorded in CG cells cultures at DIV $\leq 10$, and we replaced the A-type current model with our own model that better captures the multiple kinetic components of native $I_{\mathrm{SA}}$ in these neurons (D'Angelo et al., 2001) (see Materials and Methods). Although mDPP6 RNAi produces changes in both $I_{\mathrm{SA}}$ amplitude and kinetics, since $I_{\mathrm{SA}}$ amplitude changes in CG cells are so large, we first tested whether a change in input resistance and $I_{\mathrm{SA}}$ amplitude alone are sufficient to reproduce the changes in firing behavior we have observed with DPP6 RNAi. We therefore maintained the same kinetics for $I_{\mathrm{SA}}$ in the control and RNAi-treated conditions and varied only the amplitude of the leak current and $I_{\mathrm{SA}}$. Using typical values for control CG cells, our mod-
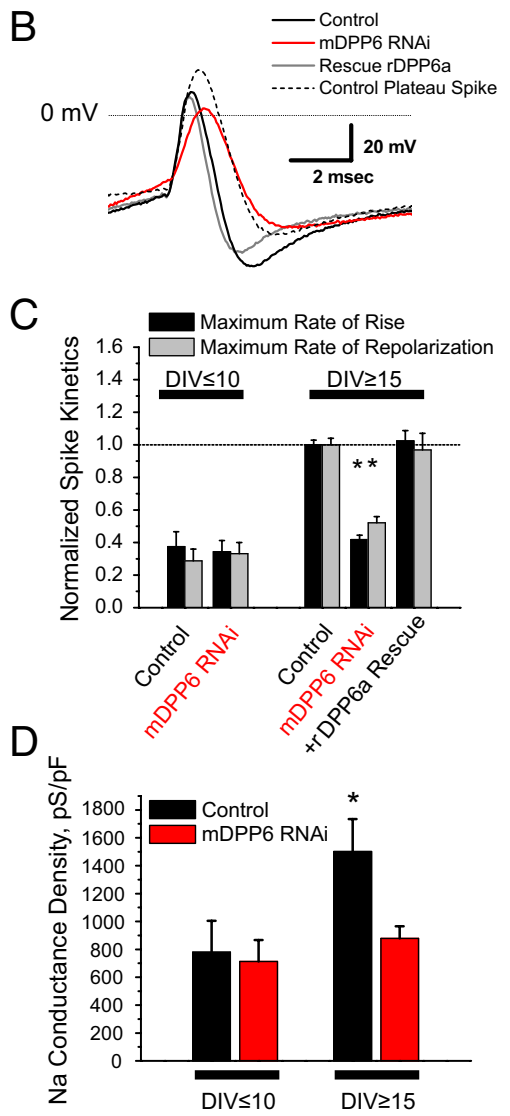

Figure 9. Action potential waveforms are different after suppression of DPP6 at later times in culture. Recordings from CG cells cultured for $15 \mathrm{~d}$ or more after treatment with the indicated lentiviral vectors. $A$, At DIV $\geq 15$, control CG cells can fire a spike in response to the initial depolarization. In $80 \%$ of cells, there is a significant delay between the first spike and the start of repetitive mDPP6 RNAi-treated CG cells, there is an early spike but the cells fail to sustain repetitive firing. Rescue with rDPP6a suggests the loss of repetitive firing is specifically attributable to the loss of DPP6 expression in these cells. $\boldsymbol{B}$, Analysis of first spike properties ffect is completely reversed by rescue with rDPP6a expression. In control cells, the first plateau spike that initiates the repetitive ing has a larger amplitude but smaller afterhyperpolarization than the initial spike. Rate of rise of the plateau spike is similar to 列

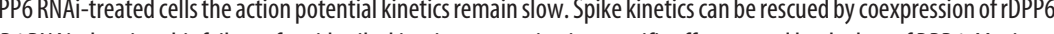
rate of rise and maximum rate of repolarization of all conditions were normalized to mean values of control spikes at DIV $\geq 15$ (data from analysis of 6-10 recordings for each condition). $D, \mathrm{Na}^{+}$channel conductance density is significantly greater in control neurons after $15 \mathrm{~d}$ in culture. In comparison, in mDPP6 RNAi-treated CG cells, the $\mathrm{Na}^{+}$channel conductance density is not significantly changed compared with that observed at $10 \mathrm{~d}$ in culture. Error bars indicate SEM.

eling closely reproduces the excitability of control neurons, as well as the delay in time to first spike observed in control CG cells even with strong current injections (Fig. $10 \mathrm{~A}$ ). In contrast, reducing the $I_{\mathrm{SA}}$ amplitude by $90 \%$ and doubling the input resistance to model an mDPP6 RNAi-treated neuron causes the model CG cell to fire at much lower current injections. First spikes are also initiated with shorter latencies in response to these current injections. We also examined the separate effects of changing input resistance or $I_{\mathrm{SA}}$ amplitude, as well as the effects of mimicking the exact steady-state and kinetic changes in $I_{\mathrm{SA}}$ produced by mDPP6 RNAi treatment (supplemental Fig. 2, available at www.jneurosci.org as supplemental material). The results show that reduction in $I_{\mathrm{SA}}$ amplitude is the dominant factor in producing a short latency spike. 
A

$10 \mathrm{pA}$

\section{Control}

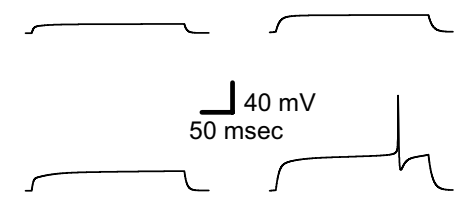

$40 \mathrm{pA}$
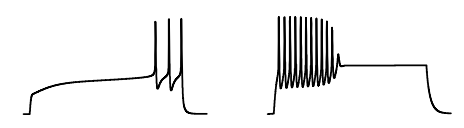

$60 \mathrm{pA}$
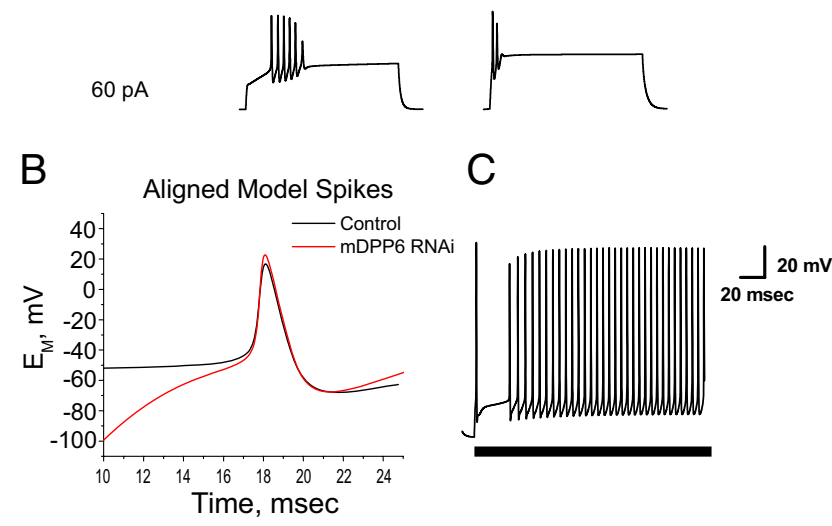

Figure 10. NEURON model of $\mathrm{CG}$ cell firing properties shows that most effects of mDPP6 RNAi can be reproduced by simply reducing the amplitude of A-type current. $A$, Singlecompartment model for a $C G$ cell reproduces the basic firing properties of the representative $C G$ cell shown in Figure 8 A. Maintaining all the current parameters from the control model and only reducing the amplitude of the $I_{S A}$ components reproduces the altered firing properties of the mDPP6 RNAi-treated neurons. $\boldsymbol{B}$, Model-generated first spikes at a current injection of $40 \mathrm{pA}$ for control CG cells are peak aligned with spikes for mDPP6 RNAi CG cells. Differences in prepotentials are attributable to the first spike occurring later during the current injection in control CG cell model. Reduction of $/_{S A}$ in mDPP6 RNAi-treated CG cell model only produces a small increase in peak amplitude and spike width, and a slight decrease in threshold potential. AHP is not significantly different between control and mDPP6 RNAi model neurons because of the inactivation of $I_{S A}$ channel in control $C G$ cells before spike initiation during the plateau. C, Firing properties of $\mathrm{CG}$ cells at later times in culture can be reproduced by increasing A-type current somatic amplitude and the amplitude of $\mathrm{Na}^{+}$current in the axon hillock.

We next compared the properties of the first spikes produced by our control and mDPP6 RNAi-treated model CG cells with the first spike properties seen in mDPP6 RNAi and control CG cell recordings (Fig. 10B). The modeling results show that the spikes of model mDPP6 RNAi and control CG cells are more similar than what is observed in actual recordings. The model shows only minimal effects of mDPP6 RNAi threshold, spike width, and peak amplitude, in the same direction as we see in actual recordings, but these changes in the model are less than what we observe. These studies also suggest that the mDPP6 RNAi neurons likely fire less repetitively because they tend to remain at higher potentials during the current injections because of higher input resistances combined with smaller AHPs (Yuan et al., 2005).

We also found that the observed spike-gap-train firing properties in older control and rDPP6a-rescued CG cells could not be readily replicated by our model. Any changes in current amplitude or kinetics sufficient to allow control spikes to occur early in the depolarization resulted in sustained firing throughout the current injection. We therefore tested a recent multicompartmental CG cell model that reproduces differential channel distributions in cell body and axon hillock (Diwakar et al., 2009). Using this model, we found that spike-gap-train type firing could be reproduced by increasing axon hillock $\mathrm{Na}^{+}$channel density and somatodendritic A-type current density from the standard parameters used in the model (Fig. 10C). Finally, we examined the effects of changing $I_{\mathrm{SA}}$ and $I_{\mathrm{Na}}$ density on initial spike kinetic properties. A doubling of $\mathrm{Na}^{+}$density resulted in a $40 \%$ increase in the maximum rate of rise with little effect on the maximum rate of recovery, suggesting that observed changes in $\mathrm{Na}^{+}$current density can explain most of the effect of mDPP6 RNAi on the rising phase of the action potential (data not shown). Finally, as predicted, changes in $I_{\mathrm{SA}}$ primarily affect the maximum rate of recovery with little to no effect on the maximum rate of rise.

\section{Effect of selective Kv4.2 elimination on $I_{\mathrm{SA}}$ and CG cell functional properties}

We find that most $I_{\mathrm{SA}}$ in CG cells is dependent on Kv4.2 expression. In cultured CG cells derived from Kv4.2 KO animals, peak $I_{\mathrm{SA}}$ is reduced by $75 \%$ compared with wild-type neurons [Kv4.2 $\left.\mathrm{KO} I_{\mathrm{SA}}, 584 \pm 103 \mathrm{pA}(n=4)\right]$, a reduction similar to that produced by mDPP6 RNAi treatment (Fig. 11 $A$; supplemental Fig. $3 A$, available at www.jneurosci.org as supplemental material). The residual $I_{\mathrm{SA}}$ in Kv4.2 KO CG cells is likely formed by Kv4.3 proteins that are also expressed in CG cells (Strassle et al., 2005). Similar to previous studies (Chen et al., 2006; Menegola and Trimmer, 2006), we find by Western blot analysis that knock-out of Kv4.2 dramatically reduces KChIP3 levels by $>90 \%$. However, we find that DPP6 is much less affected with $60 \%$ or more of the wild-type levels of protein remaining in Kv4.2 KO neurons (Fig. $11 B$ ). Thus, unlike KChIP3, the majority of the DPP6 protein is not dependent on the expression of the main $I_{\mathrm{SA}}$ channel $\alpha$-subunit protein.

Given the almost complete loss of DPP6 in CG cells treated with mDPP6 RNAi compared with 60\% normal levels of DPP6 in Kv4.2 KO neurons, we decided to see whether careful electrophysiological examination of CG cells from Kv4.2 KO animals might allow us to separate functional changes that are dependent on the loss of $I_{\mathrm{SA}}$ from those that are more specifically related to the loss of DPP6. We first used voltage-clamp analysis of the residual $I_{\mathrm{SA}}$ to identify differences in $I_{\mathrm{SA}}$ functional properties that are linked to the level of DPP6 present in the CG cell (supplemental Fig. 3, available at www.jneurosci.org as supplemental material). Although the amplitude of $I_{\mathrm{SA}}$ in CG cells from Kv4.2 $\mathrm{KO}$ animals is reduced, the kinetics and voltage dependence of the residual $I_{\mathrm{SA}}$ are not significantly different from wild-type $I_{\mathrm{SA}}$ and very different from the slowed kinetics and altered voltage dependence seen in mDPP6 RNAi-treated neurons. This result agrees with our hypothesis that DPP6 is critical for the normal gating properties of $I_{\mathrm{SA}}$ in CG cells. We also tested for potential compensatory changes in other outward Kv currents in CG cells from Kv4.2 KO animals, as previously reported in hippocampal and cortical pyramidal neurons (Chen et al., 2006; Nerbonne et al., 2008), but we did not observe any significant changes in the levels of other Kv currents or in the level of the TEA-sensitive component of outward current (data not shown).

We next examined the electrophysiological properties of Kv4.2 KO CG cells in the whole-cell current-clamp configuration. The first clear observation is that the input resistance of CG cells from $\mathrm{Kv} 4.2 \mathrm{KO}$ animals is not significantly different from control [Kv4.2 KO $\left.R_{\text {input }}, 0.9 \pm 0.1 \mathrm{G} \Omega(n=4)\right]$ but significantly different from CG cells with mDPP6 RNAi treatment in which input resistance is doubled. This result supports our previous estimates and modeling that show that a reduction in $I_{\mathrm{SA}}$ amplitude should not have a significant impact on input resistance, and suggests that changes in input resistance with mDPP6 RNAi are 
A

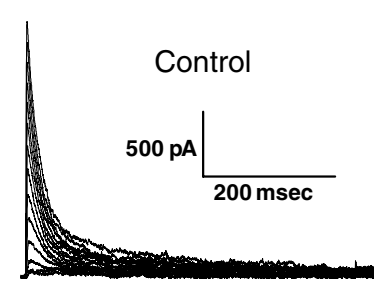

Kv4.2 KO

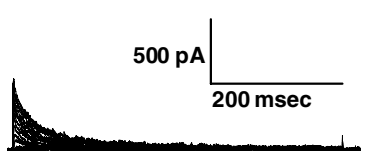

B

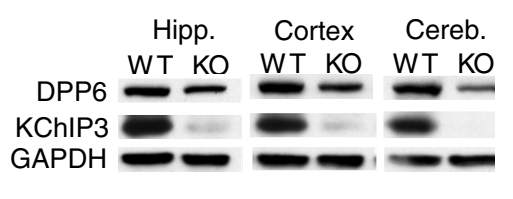

C
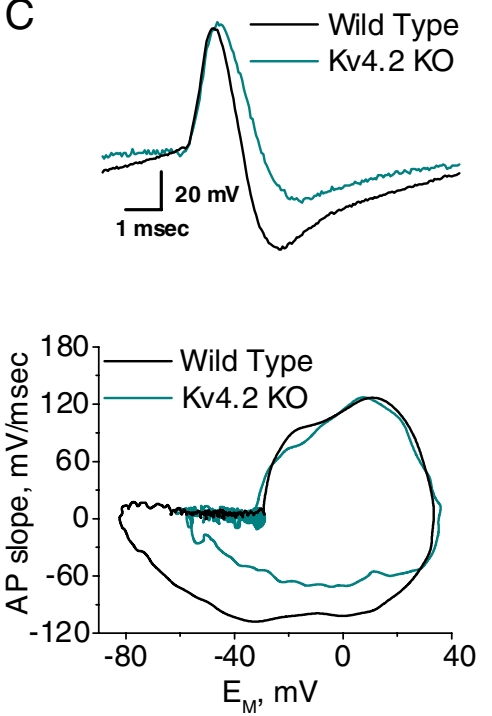

Figure 11. Kv4.2 KO reduces $I_{S A}$ amplitude, maintains DPP6 expression, and selectively affects action potential repolarization but not action potential rise. $A$, Representative current traces from wild-type control and Kv4.2 KO cultured $C G$ cells illustrate the dramatic reduction in the levels of $I_{S A}$ in Kv4.2 K0 neurons. B, Top, Western blots of hippocampus, cortex, and cerebellum from P4 wild-type and Kv4.2 K0 mice for DPP6, KChIP3, and GAPDH. Bottom, Quantitation of DPP6 and KChIP3 immunoreactivity by densitometry and normalization to GAPDH levels reveals a 90 -99\% decrease in the levels of KChIP3 but only a 25-40\% decrease in the levels of DPP6 in brains of Kv4.2 K0 animals relative to control. Kv4.2 K0 animals were identified by PCR genotyping and the absence of Kv4.2 confirmed by Western blot (data not shown). C, Top, Representative action potentials from wild-type and Kv4.2 K0 cerebellar granule cells reveal similar action potential threshold and peaks but wider spike width and shallower AHPs for Kv4.2 KO CG cells relative to control. Bottom, Representative phase plots of CG cell action potentials from control and Kv4.2 K0 animals illustrates that only the rate of repolarization but not the rate of rise of the action potential is affected by elimination of Kv4.2. Error bars indicate SEM.

specifically linked to the loss of DPP6 protein. Second, Kv4.2 KO neurons do not show the slowed rate of rise of the action potential observed with mDPP6 RNAi treatment; however, the rate of repolarization and reduced size of the AHP are similar to what we previously found with mDPP6 RNAi treatment (AP max rate of rise: control, $147.4 \pm 7.0 \mathrm{~V} / \mathrm{s} ; \mathrm{Kv} 4.2 \mathrm{KO}, 125.1 \pm 13.2 \mathrm{~V} / \mathrm{s} ; \mathrm{AP}$ max rate of repolarization: control, $-99.4 \pm 4.9 \mathrm{~V} / \mathrm{s}$; Kv4.2 KO, $-59.3 \pm 3.9 \mathrm{~V} / \mathrm{s}$ ) (Fig. 11C). Representative action potential phase plots from wild-type control and Kv4.2 KO CG cells illustrate the similar rate of rise but significantly slower rate of repolarization and shallower AHP for Kv4.2 KO CG cell spikes (Fig. $11 C$, bottom). These results suggest that the common effect of reducing $I_{\mathrm{SA}}$ is responsible for the slower repolarization and reduced AHP, whereas the loss of DPP6 is specifically related to the slower rate of rise of the action potential.

\section{Discussion}

In this study, we have examined the role of DPP6 in mouse CG cells by selectively knocking down expression of mDPP6. CG cells selectively express DPP6 at a high level, have large A-type currents, and are electrophysiologically compact; they are therefore ideal neurons in which to study the native functional role of DPP6 (Zagha et al., 2005; Nadal et al., 2006; Clark et al., 2008). Using lentiviral RNAi vectors to selectively suppress DPP6 in CG cells, we were able to examine both the biochemical and functional impact of loss of DPP6. Our motivational hypothesis, based on results from DPP6 studies in heterologous systems, posited that the primary impact of mDPP6 RNAi would be on $I_{\mathrm{SA}}$ kinetics and steady-state properties. We confirm this hypothesis in addition to discovering novel roles for DPP6. Changing the expression level of DPP6 surprisingly also results in differential regulation of $I_{\mathrm{SA}}$, leak, and $\mathrm{Na}^{+}$channels. The effects on leak and $\mathrm{Na}^{+}$currents are not seen in a Kv4.2 KO CG cells with greatly reduced $I_{\mathrm{SA}}$, but DPP6 protein levels within $60 \%$ of normal, suggesting that loss of $I_{\mathrm{SA}}$ alone is not sufficient to explain these observations. DPP6 therefore appears capable of resculpting CG cell electrophysiological properties from that of a neuron firing a slow, single action potential to a neuron capable of rapid, repetitive firing likely required for normal cerebellar function.

Our studies clearly show that, in CG cells, loss of DPP6 dramatically reduces $I_{\mathrm{SA}}$ amplitude and produces rightward shifts in gating midpoints and a slowing of gating kinetics. To confirm that suppression of $I_{\mathrm{SA}}$ is a specific consequence of the loss of mDPP6, we show that the effects of mDPP6 RNAi on $I_{\mathrm{SA}}$ amplitude can be effectively reversed by coexpression of rat DPP6a resistant to RNAi. These effects of DPP6 RNAi in native CG cells mirror the effects of DPP6 in heterologous expression systems, in which DPP6 increases Kv4.2 channel expression, left shifts gating midpoints, and accelerates channel-gating properties (Nadal et al., 2003; Jerng et al., 2005, 2009; Amarillo et al., 2008).

Our biochemical studies show that DPP6 is required for normal $I_{\mathrm{SA}}$ channel protein levels in both CG cells and hippocampal neurons, and thus suggest a general role for DPLP in establishing normal levels of $I_{\mathrm{SA}}$ channel proteins in neurons. In CG cells, the loss of $I_{\mathrm{SA}}$ channel proteins results in a clear, functional consequence observed as a $>85 \%$ reduction in $I_{\mathrm{SA}}$ amplitude by somatic whole-cell patch clamp. In contrast, a recent DPP6 RNAi study in rat hippocampal neurons found gating changes in somatic $I_{\mathrm{SA}}$ similar to those we have reported here, but reported no change in the amplitude of somatic $I_{\mathrm{SA}}$ (Kim et al., 2008). It is important to note, however, that recordings in CG cells are more likely to accurately reflect global functional changes since somatic whole-cell patch clamp affords better voltage-clamp control in CG cells than hippocampal neurons. Based on the size of the pyramidal neuron dendritic arbor and the much greater amplitude of $I_{\mathrm{SA}}$ in pyramidal neuron dendrites (Hoffman et al., 1997; Johnston et al., 2000), we predict that our hippocampal neuron Western blot results are mostly reflective of changes in cellular compartments that cannot be voltage clamped from the soma in 
these neurons. To test the hypothesis that DPP6 RNAi produces changes in the amplitude of pyramidal neuron, $I_{\mathrm{SA}}$ will require direct patch-clamp recordings of $I_{\mathrm{SA}}$ from hippocampal pyramidal neuron dendrites.

Residual $I_{\mathrm{SA}}$ channel gating in DPP6 RNAi-treated neurons behaves similarly to what would be predicted for a binary $\mathrm{Kv} 4 /$ KChIP $I_{\text {SA }}$ complex. The observed slower time to peak is in accordance with values reported for $\mathrm{Kv} 4 / \mathrm{KChIP}$ complexes in heterologous expression systems and clearly reflects a loss of the acceleration in activation gating produced by DPP6 (Nadal et al., 2003; Jerng et al., 2005, 2009; Dougherty and Covarrubias, 2006). Macroscopic inactivation of residual $I_{\mathrm{SA}}$ in mDPP6 RNAi CG cells is significantly slower than control-treated neurons and slows with increasing depolarization, also compatible with a binary $\mathrm{Kv} 4 / \mathrm{KChIP} I_{\mathrm{SA}}$ complex as measured in heterologous systems (An et al., 2000; Jerng et al., 2005, 2009). Indeed, the slowing of inactivation with depolarization is characteristic of Kv4 channels that have bound KChIPs and is not seen with Kv4 channels lacking KChIPs, either expressed alone or with DPLPs (An et al., 2000; Jerng et al., 2005, 2009). Finally, $I_{\mathrm{SA}}$ recovery from inactivation in mDPP6 RNAi-infected CG cells is three times slower than $I_{\mathrm{SA}}$ recovery in control CG cells and is similar to what is observed in heterologous expression systems for binary Kv4/ KChIP $I_{\text {SA }}$ complexes (An et al., 2000; Jerng et al., 2005, 2009). Together, voltage-dependent steady-state and kinetic properties of residual $I_{\mathrm{SA}}$ strongly suggest that residual $I_{\mathrm{SA}}$ channels in DPP6 RNAi-treated CG cells primarily consist of $I_{\mathrm{SA}}$ channels formed by Kv4/KChIP binary complexes.

It is initially surprising that KChIPs present in the neuron are not sufficient to maintain normal levels of $I_{\mathrm{SA}}$ channel proteins and functional surface channels. In heterologous expression systems, most KChIP variants stabilize $\mathrm{Kv} 4$ proteins and promote very large increases in surface expression for Kv4 channels (Shi et al., 1996; An et al., 2000; Bähring et al., 2001; Rhodes et al., 2004). Recent evidence has shown that a subset of KChIPs containing a KIS domain, some of which are expressed in CG cells, do not promote surface expression (Holmqvist et al., 2002; Jerng and Pfaffinger, 2008; Seikel and Trimmer, 2009). It is possible that our results can be explained by KIS variant KChIPs that are normally present on CG cell $I_{\mathrm{SA}}$ channels and might prevent normal surface expression of $I_{\mathrm{SA}}$ channels if DPP6 is not present. Residual $I_{\mathrm{SA}}$ can be explained by surface expression of a subpopulation of channels that by chance lack KIS variant KChIPs or possibly by $I_{\mathrm{SA}}$ channels with subnormal DPP6 stoichiometry, since RNAi may not eliminate $100 \%$ of the DPP6 protein in infected neurons.

At early times in culture, first spike latency is dramatically reduced by mDPP6 RNAi. Our modeling suggests that the reduction in $I_{\mathrm{SA}}$ amplitude likely dominates the effect on spike latency. Previous studies have found that overexpression of Kv4.2 in CG cells increases first spike latency, whereas expression of a Kv4 dominant negative has the opposite effect (Shibata et al., 2000). A similar role for $I_{\mathrm{SA}}$ channels in shaping the initial response to current injection have been found in other neuron types (Saito and Isa, 2000; Yuan et al., 2005). Combined with the lower input resistance of DPP6-expressing CG cells, DPP6 expression makes it much less likely that CG cells will spike during early times in culture. The suppression of early spiking activity by DPP6 during development at a time when the nervous system is establishing connections through activity-dependent plasticity is likely to have important consequences for nervous system development (Didier et al., 1994; Aamodt and Constantine-Paton, 1999; Shalizi et al., 2006; D’Angelo and De Zeeuw, 2009).
With increasing time in culture, the overall effect of DPP6 on excitability changes. By $15 \mathrm{~d}$ in culture, the presence of DPP6 dramatically changes the firing phenotype of CG cells. Without DPP6, CG cells fire a single, kinetically slow action potential. With DPP6, we observe rapid high-frequency firing of kinetically rapid action potentials. A key factor in this switch appears to be the DPP6-dependent increase in the density of functional $\mathrm{Na}^{+}$channels by almost twofold at $15 \mathrm{~d}$ in culture. Combined with the sixfold greater $I_{\mathrm{SA}}$ conductance density and more rapid kinetics, the acceleration of spike depolarization and repolarization rates by DPP6 are readily explained. A complete understanding of all the molecular factors underlying the exact firing properties of CG cell under different conditions will require a more detailed understanding of where the conductance changes are occurring within the neuron and the precise nature of the changes in channel properties occurring within these subcellular compartments.

In conclusion, our studies strongly support an important role for DPP6 in regulating the electrophysiological properties of CG cells. DPP6 is shown to play a vital role in establishing the functional level of $I_{\mathrm{SA}}$ in a neuron and providing that channel with its characteristic rapid voltage-dependent gating properties. Based on our preliminary studies in hippocampal neurons, we propose that DPP6 may be generally important for controlling $I_{\mathrm{SA}}$ channel protein levels in many neurons. In addition, our studies suggest a role for DPP6 in regulating other channels, thus tuning neuronal firing properties. It seems likely that disregulation of DPP6 could have important implications for human health. Several recent studies have suggested links between DPP6 and DPP10 and human diseases (Allen et al., 2003; Marshall et al., 2008; van Es et al., 2008; Alders et al., 2009). It will be important in the future to determine whether cells from patients with these diseases show functional alterations in excitability consistent with the roles we have observed for DPP6 in these studies.

\section{References}

Aamodt SM, Constantine-Paton M (1999) The role of neural activity in synaptic development and its implications for adult brain function. Adv Neurol 79:133-144.

Alders M, Koopmann TT, Christiaans I, Postema PG, Beekman L, Tanck MW, Zeppenfeld K, Loh P, Koch KT, Demolombe S, Mannens MM, Bezzina CR, Wilde AA (2009) Haplotype-sharing analysis implicates chromosome 7q36 harboring DPP6 in familial idiopathic ventricular fibrillation. Am J Hum Genet 84:468-476.

Allen M, Heinzmann A, Noguchi E, Abecasis G, Broxholme J, Ponting CP, Bhattacharyya S, Tinsley J, Zhang Y, Holt R, Jones EY, Lench N, Carey A, Jones H, Dickens NJ, Dimon C, Nicholls R, Baker C, Xue L, Townsend E, et al. (2003) Positional cloning of a novel gene influencing asthma from chromosome 2q14. Nat Genet 35:258-263.

Amarillo Y, De Santiago-Castillo JA, Dougherty K, Maffie J, Kwon E, Covarrubias M, Rudy B (2008) Ternary Kv4.2 channels recapitulate voltage-dependent inactivation kinetics of A-type $\mathrm{K}^{+}$channels in cerebellar granule neurons. J Physiol 586:2093-2106.

An WF, Bowlby MR, Betty M, Cao J, Ling HP, Mendoza G, Hinson JW, Mattsson KI, Strassle BW, Trimmer JS, Rhodes KJ (2000) Modulation of A-type potassium channels by a family of calcium sensors. Nature 403:553-556.

Bähring R, Dannenberg J, Peters HC, Leicher T, Pongs O, Isbrandt D (2001) Conserved Kv4 N-terminal domain critical for effects of $\mathrm{Kv}$ channelinteracting protein 2.2 on channel expression and gating. J Biol Chem 276:23888-23894.

Bardoni R, Belluzzi O (1993) Kinetic study and numerical reconstruction of A-type current in granule cells of rat cerebellar slices. J Neurophysiol 69:2222-2231.

Barry PH (1994) JPCalc, a software package for calculating liquid junction potential corrections in patch-clamp, intracellular, epithelial and bilayer 
measurements and for correcting junction potential measurements. J Neurosci Methods 51:107-116.

Bean BP (2007) The action potential in mammalian central neurons. Nat Rev Neurosci 8:451-465.

Brummelkamp TR, Bernards R, Agami R (2002) A system for stable expression of short interfering RNAs in mammalian cells. Science 296:550-553.

Cai X, Liang CW, Muralidharan S, Kao JP, Tang CM, Thompson SM (2004) Unique roles of SK and Kv4.2 potassium channels in dendritic integration. Neuron 44:351-364.

Chen X, Yuan LL, Zhao C, Birnbaum SG, Frick A, Jung WE, Schwarz TL, Sweatt JD, Johnston D (2006) Deletion of Kv4.2 gene eliminates dendritic A-type $\mathrm{K}^{+}$current and enhances induction of long-term potentiation in hippocampal CA1 pyramidal neurons. J Neurosci 26:12143-12151.

Clark BD, Kwon E, Maffie J, Jeong HY, Nadal M, Strop P, Rudy B (2008) DPP6 localization in brain supports function as a Kv4 channel associated protein. Front Mol Neurosci 1:8.

Covarrubias M, Bhattacharji A, De Santiago-Castillo JA, Dougherty K, Kaulin YA, Na-Phuket TR, Wang G (2008) The neuronal Kv4 channel complex. Neurochem Res 33:1558-1567.

D'Angelo E, De Zeeuw CI (2009) Timing and plasticity in the cerebellum: focus on the granular layer. Trends Neurosci 32:30-40.

D’Angelo E, Nieus T, Maffei A, Armano S, Rossi P, Taglietti V, Fontana A, Naldi G (2001) Theta-frequency bursting and resonance in cerebellar granule cells: experimental evidence and modeling of a slow $\mathrm{K}^{+}$. dependent mechanism. J Neurosci 21:759-770.

Didier M, Mienville JM, Soubrié P, Bockaert J, Berman S, Bursztajn S, Pin JP (1994) Plasticity of NMDA receptor expression during mouse cerebellar granule cell development. Eur J Neurosci 6:1536-1543.

Diwakar S, Magistretti J, Goldfarb M, Naldi G, D’Angelo E (2009) Axonal $\mathrm{Na}^{+}$channels ensure fast spike activation and back-propagation in cerebellar granule cells. J Neurophysiol 101:519-532.

Dougherty K, Covarrubias M (2006) A dipeptidyl aminopeptidase-like protein remodels gating charge dynamics in Kv4.2 channels. J Gen Physiol 128:745-753.

Hines ML, Carnevale NT (2001) NEURON: a tool for neuroscientists. Neuroscientist 7:123-135.

Hoffman DA, Magee JC, Colbert CM, Johnston D (1997) $\mathrm{K}^{+}$channel regulation of signal propagation in dendrites of hippocampal pyramidal neurons. Nature 387:869-875.

Holmqvist MH, Cao J, Hernandez-Pineda R, Jacobson MD, Carroll KI, Sung MA, Betty M, Ge P, Gilbride KJ, Brown ME, Jurman ME, Lawson D, Silos-Santiago I, Xie Y, Covarrubias M, Rhodes KJ, Distefano PS, An WF (2002) Elimination of fast inactivation in Kv4 A-type potassium channels by an auxiliary subunit domain. Proc Natl Acad Sci U S A 99:1035-1040.

Jerng HH, Pfaffinger PJ (2008) Multiple Kv channel-interacting proteins contain an $\mathrm{N}$-terminal transmembrane domain that regulates Kv4 channel trafficking and gating. J Biol Chem 283:36046-36059.

Jerng HH, Qian Y, Pfaffinger PJ (2004a) Modulation of Kv4.2 channel expression and gating by dipeptidyl peptidase 10 (DPP10). Biophys J 87:2380-2396.

Jerng HH, Pfaffinger PJ, Covarrubias M (2004b) Molecular physiology and modulation of somatodendritic A-type potassium channels. Mol Cell Neurosci 27:343-369.

Jerng HH, Kunjilwar K, Pfaffinger PJ (2005) Multiprotein assembly of Kv4.2, KChIP3 and DPP10 produces ternary channel complexes with $I_{\mathrm{SA}}$-like properties. J Physiol 568:767-788.

Jerng HH, Lauver AD, Pfaffinger PJ (2007) DPP10 splice variants are localized in distinct neuronal populations and act to differentially regulate the inactivation properties of Kv4-based ion channels. Mol Cell Neurosci 35:604-624.

Jerng HH, Dougherty K, Covarrubias M, Pfaffinger PJ (2009) A novel $\mathrm{N}$-terminal motif of dipeptidyl peptidase-like proteins inactivates $\mathrm{K}_{\mathrm{v}} 4.2$ channels by a pore-blocking mechanism. Channels (Austin) 3:448-461.

Johnston D, Hoffman DA, Magee JC, Poolos NP, Watanabe S, Colbert CM, Migliore M (2000) Dendritic potassium channels in hippocampal pyramidal neurons. J Physiol 525:75-81.

Kim J, Nadal MS, Clemens AM, Baron M, Jung SC, Misumi Y, Rudy B, Hoffman DA (2008) Kv4 accessory protein DPPX (DPP6) is a critical regulator of membrane excitability in hippocampal CA1 pyramidal neurons. J Neurophysiol 100:1835-1847.
Korbo L, Andersen BB, Ladefoged O, Møller A (1993) Total numbers of various cell types in rat cerebellar cortex estimated using an unbiased stereological method. Brain Res 609:262-268.

Lauver A, Yuan LL, Jeromin A, Nadin BM, Rodríguez JJ, Davies HA, Stewart MG, Wu GY, Pfaffinger PJ (2006) Manipulating Kv4.2 identifies a specific component of hippocampal pyramidal neuron A-current that depends upon Kv4.2 expression. J Neurochem 99:1207-1223.

Levi G, Aloisi F, Ciotti MT, Gallo V (1984) Autoradiographic localization and depolarization-induced release of acidic amino acids in differentiating cerebellar granule cell cultures. Brain Res 290:77-86.

Lois C, Hong EJ, Pease S, Brown EJ, Baltimore D (2002) Germline transmission and tissue-specific expression of transgenes delivered by lentiviral vectors. Science 295:868-872.

Maffie J, Blenkinsop T, Rudy B (2009) A novel DPP6 isoform (DPP6-E) can account for differences between neuronal and reconstituted A-type $\mathrm{K}^{+}$ channels. Neurosci Lett 449:189-194.

Marionneau C, LeDuc RD, Rohrs HW, Link AJ, Townsend RR, Nerbonne JM (2009) Proteomic analyses of native brain $\mathrm{K}_{\mathrm{V}} 4.2$ channel complexes. Channels (Austin) 3:284-294.

Marshall CR, Noor A, Vincent JB, Lionel AC, Feuk L, Skaug J, Shago M, Moessner R, Pinto D, Ren Y, Thiruvahindrapduram B, Fiebig A, Schreiber S, Friedman J, Ketelaars CE, Vos YJ, Ficicioglu C, Kirkpatrick S, Nicolson $\mathrm{R}$, Sloman L, et al. (2008) Structural variation of chromosomes in autism spectrum disorder. Am J Hum Genet 82:477-488.

Menegola M, Trimmer JS (2006) Unanticipated region- and cell-specific downregulation of individual KChIP auxiliary subunit isotypes in Kv4.2 knock-out mouse brain. J Neurosci 26:12137-12142.

Mitta B, Rimann M, Fussenegger M (2005) Detailed design and comparative analysis of protocols for optimized production of high-performance HIV-1-derived lentiviral particles. Metab Eng 7:426-436.

Nadal MS, Ozaita A, Amarillo Y, Vega-Saenz de Miera E, Ma Y, Mo W, Goldberg EM, Misumi Y, Ikehara Y, Neubert TA, Rudy B (2003) The CD26-related dipeptidyl aminopeptidase-like protein DPPX is a critical component of neuronal A-type $\mathrm{K}^{+}$channels. Neuron 37:449-461.

Nadal MS, Amarillo Y, Vega-Saenz de Miera E, Rudy B (2006) Differential characterization of three alternative spliced isoforms of DPPX. Brain Res 1094:1-12.

Nerbonne JM, Gerber BR, Norris A, Burkhalter A (2008) Electrical remodelling maintains firing properties in cortical pyramidal neurons lacking KCND2-encoded A-type $\mathrm{K}^{+}$currents. J Physiol 586:1565-1579.

Okazawa M, Abe H, Katsukawa M, Iijima K, Kiwada T, Nakanishi S (2009) Role of calcineurin signaling in membrane potential-regulated maturation of cerebellar granule cells. J Neurosci 29:2938-2947.

Osorio N, Alcaraz G, Padilla F, Couraud F, Delmas P, Crest M (2005) Differential targeting and functional specialization of sodium channels in cultured cerebellar granule cells. J Physiol 569:801-816.

Ramakers GM, Storm JF (2002) A postsynaptic transient $\mathrm{K}^{+}$current modulated by arachidonic acid regulates synaptic integration and threshold for LTP induction in hippocampal pyramidal cells. Proc Natl Acad Sci U S A 99:10144-10149.

Rhodes KJ, Carroll KI, Sung MA, Doliveira LC, Monaghan MM, Burke SL, Strassle BW, Buchwalder L, Menegola M, Cao J, An WF, Trimmer JS (2004) KChIPs and Kv4 $\alpha$ subunits as integral components of A-type potassium channels in mammalian brain. J Neurosci 24:7903-7915.

Saito Y, Isa T (2000) Voltage-gated transient outward currents in neurons with different firing patterns in rat superior colliculus. J Physiol 528:91-105.

Seikel E, Trimmer JS (2009) Convergent modulation of Kv4.2 channel alpha subunits by structurally distinct DPPX and KChIP auxiliary subunits. Biochemistry 48:5721-5730.

Serôdio P, Rudy B (1998) Differential expression of Kv4 K ${ }^{+}$channel subunits mediating subthreshold transient $\mathrm{K}^{+}$(A-type) currents in rat brain. J Neurophysiol 79:1081-1091.

Shalizi A, Gaudillière B, Yuan Z, Stegmüller J, Shirogane T, Ge Q, Tan Y, Schulman B, Harper JW, Bonni A (2006) A calcium-regulated MEF2 sumoylation switch controls postsynaptic differentiation. Science 311:1012-1017.

Shi G, Nakahira K, Hammond S, Rhodes KJ, Schechter LE, Trimmer JS (1996) Beta subunits promote $\mathrm{K}^{+}$channel surface expression through effects early in biosynthesis. Neuron 16:843-852. 
Shibata R, Nakahira K, Shibasaki K, Wakazono Y, Imoto K, Ikenaka K (2000) A-type $\mathrm{K}^{+}$current mediated by the $\mathrm{Kv} 4$ channel regulates the generation of action potential in developing cerebellar granule cells. J Neurosci 20:4145-4155.

Strassle BW, Menegola M, Rhodes KJ, Trimmer JS (2005) Light and electron microscopic analysis of KChIP and Kv4 localization in rat cerebellar granule cells. J Comp Neurol 484:144-155.

Takimoto K, Hayashi Y, Ren X, Yoshimura N (2006) Species and tissue differences in the expression of DPPY splicing variants. Biochem Biophys Res Commun 348:1094-1100.

Tiscornia G, Singer O, Verma IM (2006) Production and purification of lentiviral vectors. Nat Protoc 1:241-245.

van Es MA, van Vught PW, Blauw HM, Franke L, Saris CG, Van den Bosch L, de Jong SW, de Jong V, Baas F, van't Slot R, Lemmens R, Schelhaas HJ, Birve A, Sleegers K, Van Broeckhoven C, Schymick JC, Traynor BJ, Wokke JH, Wijmenga C, Robberecht W, et al. (2008) Genetic variation in DPP6 is associated with susceptibility to amyotrophic lateral sclerosis. Nat Genet 40:29-31.

Watanabe S, Hoffman DA, Migliore M, Johnston D (2002) Dendritic K ${ }^{+}$channels contribute to spike-timing dependent long-term potentiation in hippocampal pyramidal neurons. Proc Natl Acad Sci U S A 99:8366-8371.

Xiong H, Kovacs I, Zhang Z (2004) Differential distribution of KChIPs mRNAs in adult mouse brain. Brain Res Mol Brain Res 128:103-111.

Xue M, Ma C, Craig TK, Rosenmund C, Rizo J (2008) The Janus-faced nature of the $\mathrm{C}_{2} \mathrm{~B}$ domain is fundamental for synaptotagmin-1 function. Nat Struct Mol Biol 15:1160-1168.

Yuan W, Burkhalter A, Nerbonne JM (2005) Functional role of the fast transient outward $\mathrm{K}^{+}$current $I_{\mathrm{A}}$ in pyramidal neurons in (rat) primary visual cortex. J Neurosci 25:9185-9194.

Zagha E, Ozaita A, Chang SY, Nadal MS, Lin U, Saganich MJ, McCormack T, Akinsanya KO, Qi SY, Rudy B (2005) DPP10 modulates Kv4-mediated A-type potassium channels. J Biol Chem 280:18853-18861. 